\title{
Selection of borehole temperature depth profiles for regional climate reconstructions
}

\author{
C. Chouinard and J.-C. Mareschal \\ GEOTOP-UQAM-McGill, Centre de Recherche en Géochimie et en Géodynamique, Univ. du Québec à Montréal, Canada
}

Received: 21 December 2006 - Published in Clim. Past Discuss.: 19 January 2007

Revised: 16 April 2007 - Accepted: 22 May 2007 - Published: 11 June 2007

\begin{abstract}
Borehole temperature depth profiles are commonly used to infer time variations in the ground surface temperature on centennial time scales. We compare different procedures to obtain a regional ground surface temperature history (GSTH) from an ensemble of borehole temperature depth profiles. We address in particular the question of selecting profiles that are not contaminated by non climatic surface perturbations and we compare the joint inversion of all the profiles with the average of individual inversions. Very few profiles of the Canadian data set meet the selection criteria (e.g. only 13 out of 73 profiles in Manitoba and Saskatchewan were retained). We show that the resolution and the stability of the inversion of selected profiles are much improved over those for a complete data set. When profiles have been selected, the average GSTH of individual inversions and the GSTH of the joint inversion are almost identical. This is not observed when the entire data set is inverted: the average of individual inversions is different from the joint inversion. We also show that the joint inversion of very noisy data sets does not improve the resolution but, on the contrary, causes strong instabilities in the inversion. When the profiles that are affected by noise can not be eliminated, averaging of the individual inversions yields the most stable result, but with very poor resolution.
\end{abstract}

\section{Introduction}

In recent years, borehole temperature data have been used to provide additional evidence for recent climatic changes in several parts of the world (e.g. Cermak, 1971; Vasseur et al., 1983; Lachenbruch and Marshall, 1986; Nielsen and Beck, 1989; Beltrami et al., 1992; Wang, 1992; Bodri and Cermak, 1997; Pollack et al., 1996). Indeed, transient surface temper-

Correspondence to: J.-C. Mareschal

(jcm@olympus.geotop.uqam.ca) ature perturbations propagate downward and, although attenuated, are recorded in the Earth's subsurface as perturbations of a steady state temperature regime.

Because surface temperature oscillations are damped over a length scale $\delta$ (skin depth) which depends on their frequency $\omega$ and on thermal diffusivity $\kappa(\delta=\sqrt{\kappa / 2 \omega})$, the earth acts as a filter and the record of the ground surface temperature history (GSTH) is blurred. Because of the low thermal diffusivity of rocks $\left(\approx 10^{-6} \mathrm{~m}^{2} \mathrm{~s}^{-1}\right)$, the short period oscillations, such as the diurnal or annual cycles, have skin depth ranging from a few centimetres to a couple of meters. Variations of ground surface temperature of the last 200-300 years are recorded in the first 200 meters, whereas the effect of the post-glacial warming is observed down to $2500 \mathrm{~m}$. The interpretation of temperature profiles in terms of the GSTH presents all the characteristics of ill-posed geophysical inversion problems: their solution is not unique and it is unstable (e.g. Jackson, 1972; Tikhonov and Arsenin, 1977; Menke, 1989; Parker, 1994).

The first application of inversion techniques to infer the GSTH from borehole temperature profile was the study by Vasseur et al. (1983). In the last fifteen years, several papers have addressed the problem of inversion of borehole temperature data and different methods have been proposed to invert the GSTH from one or several temperature profiles. Many other papers deal "empirically" with practical considerations.

The interpretation of borehole temperature profiles is based on the one dimensional heat equation; it assumes that a uniform boundary condition is applied on a plane surface and that physical properties only depend on depth. Although corrections can be applied to correct heat flow for the effect of topography (Blackwell et al., 1980), this is rarely done in climate studies because the amplitude of the climatic signals is often smaller than the uncertainty on these corrections. Other variations in surface boundary condition can affect the temperature measured at depth and need to be accounted for:

Published by Copernicus Publications on behalf of the European Geosciences Union. 
proximity to lakes or large rivers, recent forest fires, changes in vegetation cover, deforestation. Other perturbations include refraction by lateral changes in thermal conductivity, water circulation in the borehole, etc. These effects need to be well documented since they produce distortions of the temperature profiles similar to those produced by climate change and they might overshadow any real climatic signal in a GSTH. Until recently, borehole temperature depth profiles were not logged to infer past climates, but for heat flow measurements. For heat flow studies, corrections are often small and can be avoided when boreholes are deep and the surface effects become negligible. But for climate studies, the signal is recorded in the shallow part of the profile which is most affected by noise.

It had been hoped that the problem of noise could be alleviated through regional GSTH studies, performed by inverting several borehole temperature profiles within a given region (Beltrami and Mareschal, 1992; Pollack et al., 1996). Such studies assume that variations of air surface temperature trends and thus of ground surface temperatures remain correlated over distances $\approx 500 \mathrm{~km}$ (Hansen and Lebedeff, 1987; Jones et al., 1999). Two methods can be used to determine a regional GSTH: all the borehole temperature profiles are inverted simultaneously to obtain the common GSTH, or each profile is inverted separately and the individual GSTHs are averaged. If noise is random and uncorrelated, the simultaneous inversion of a given data-set, either local or regional, should theoretically yield a GSTH with a better signal to noise ratio than an average of individual inversions. This assumes that the noise is uncorrelated and that there is no systematic bias in the perturbations of the temperature profile. This latter condition is unlikely to be met for practical reasons: for instance, boreholes located on the shore of a lake can be (and are) logged, but boreholes in the middle of a lake never are. Boreholes drilled in lakes are normally cemented; even when they are not, the casing is never left sticking out of the lake and has been pulled out. Some authors (Lewis, 1998) have thus argued that the error associated to GSTH will systematically be biased towards a warming of the ground surface. The argument is that in most cases, human and/or natural effects on the energy balance at the ground surface will cause a gain of energy by the ground (clear-cutting of forested areas, pollution effects on vegetation cover, forest fires, etc.). Previous studies with poorly documented site conditions retained all the boreholes and might have overestimated the warming trend (Beltrami et al., 1992; Beltrami and Mareschal, 1992).

When the conditions at the sites are well documented, one could eliminate the temperature profiles that are perturbed by surface conditions. In general, very few boreholes meet strict criteria, and the majority of the logged boreholes in a region are rejected. For example, in two recent studies only 15 and $50 \%$ of the logged boreholes within the study areas were retained (Guillou-Frottier et al., 1998; Gosselin and Mareschal, 2003).
The correlation of individual inversions of temperature profiles is often weak whether they come from the same region (Gosselin and Mareschal, 2003) or cover a wide part of the Earth surface (Harris and Chapman, 2001). Consequently, the GSTH averaging all the individual inversions has very poor resolution (Pollack et al., 1998). It was hoped that the simultaneous inversion of profiles from a region that have recorded the same GSTH would improve resolution because the signal in the GSTH should be correlated and the noise is not (Beltrami and Mareschal, 1992, 1995; Clauser and Mareschal, 1995; Pollack et al., 1996). In practice, this did not turn out to be true (Huang et al., 2000; Gosselin and Mareschal, 2003). There are several reasons that joint inversion did not do much to improve the results.

1. The number of temperature profiles remains small and insufficient to produce a significant improvement in the signal to noise ratio which is $\propto \sqrt{N}$.

2. The assumption that the GSTHs are identical is almost never verified. One would not expect it to hold when the data cover a very wide region of the Earth. Even at the regional scale, visual inspection of the reduced temperature profiles reveals that they have not recorded the same GSTH. Thus, the joint inversion of real data seldom improves signal/noise ratio; sometimes it decreases this ratio.

3. Even when the GSTHs are identical at all sites, the records will be consistent only if the thermal diffusivity at each site is well determined. The danger of adjusting physical properties is that the GSTHs may appear well correlated when they are not.

4. The resolution is limited by the profile with the highest noise level which determines how much regularization is required (Beltrami et al., 1997).

5. Beltrami et al. (1997) have emphasized the need to combine profiles with comparable vertical depth in order to avoid bias. The minimum depth sampled varies much between boreholes, because measurements above the water table are extremely noisy and are often discarded. This is an important bias because temperature perturbations are largest near the surface.

Different authors have calculated the GSTH (local or regional) from the raw or the "reduced" temperature depth profiles. The reduced temperature profile is obtained by removing from the data a reference temperature profile, obtained by upward continuation of the lowermost part of the profile, assumed to be near steady state. This preprocessing of data allows to infer warming or cooling by visual inspection of these reduced profiles. But it may also be useful to improve the results of the inversions using the singular value decomposition algorithm to determine regional GSTH. 


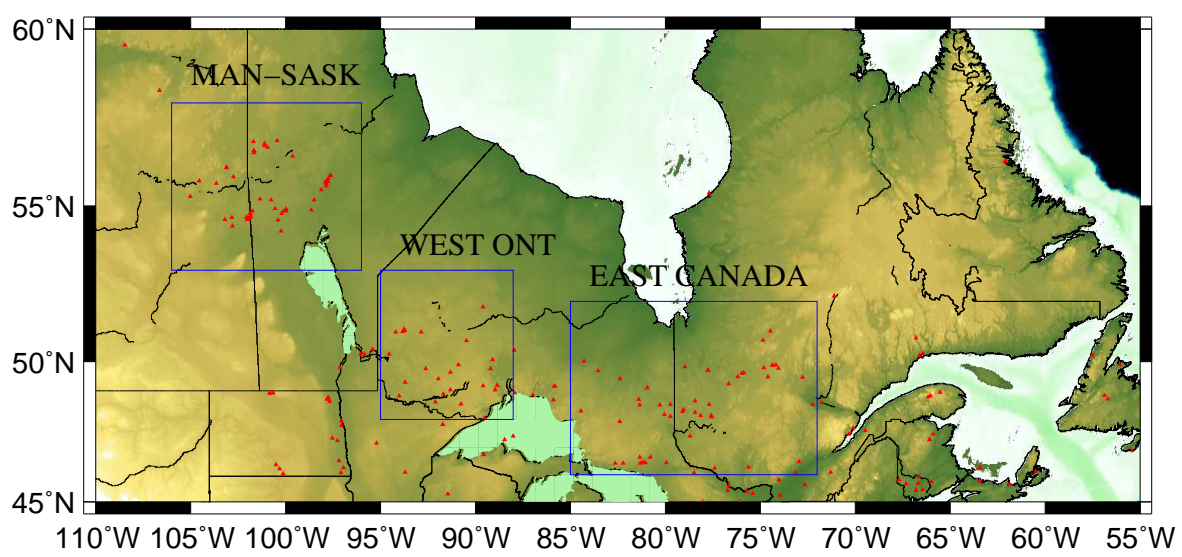

Fig. 1. Location map showing the three regions and the data used in this study. The blue rectangles delimits the three regions. The red triangles show all the borehole temperature depth profiles available in central and eastern Canada.

So far, there is no consensus among researchers on the best procedure to obtain a regional GSTH (simultaneous inversion vs. average of individual inversions, selection of borehole temperature profiles unaffected by non-climatic perturbations vs. "indiscriminate" use of all the borehole temperature profiles, reduced vs raw temperature profiles). No systematic studies were conducted because there were not enough measurements in a given region to make statistically relevant comparisons. During the past 20 years, the GEOTOP-IPGP (Institut de Physique du Globe de Paris) research team has logged 338 boreholes at more than 100 different sites across south-central and south-eastern Canada (Fig. 1). Because these sites are distributed in three main regions, northern Manitoba and Saskatchewan, north-western Ontario, and eastern Ontario and Quebec, these borehole temperature data are appropriate to conduct regional studies, and the number of data in each region is sufficient to compare results from the different procedures.

\section{Theoretical framework}

\subsection{General formulation - the direct problem}

Usually, the data consist of a few temperature profiles, thermal conductivity, and heat production measurements. Because the temperature profiles are sparse and the boreholes where they were obtained are far apart, it is common to neglect lateral variations in physical properties, and in the boundary conditions. These assumptions are not always satisfied either because the surface boundary condition can vary (effect of lakes, vegetation cover, topography, etc.) or because physical properties vary horizontally and there may be refraction. This is likely to be the case with mining exploration boreholes that target very local mineralized bodies. In general, however, there is not enough information on the 3-
D conductivity variations and insufficient data to warrant a three dimensional model.

For a layered earth, the steady-state temperature profile can be written as:

$$
\begin{gathered}
T_{e} z=T_{\mathrm{ref}}+q_{\mathrm{ref}} R(z)-M(z) \\
R(z)=\int_{0}^{z} \frac{d z^{\prime}}{\lambda\left(z^{\prime}\right)} \\
M(z)=\int_{0}^{z} \frac{d z^{\prime}}{\lambda\left(z^{\prime}\right)} \int_{0}^{z^{\prime}} d z^{\prime \prime} H\left(z^{\prime \prime}\right)
\end{gathered}
$$

where $\lambda$ is the thermal conductivity, $H$ is the heat generation, $z$ is depth, positive downward. The heat flow $q_{\text {ref }}$ is taken positive upward. If a temperature perturbation $T_{0}(t)$ is applied uniformly on the surface $z=0$, the temperature in a homogeneous half space is given by (Carslaw and Jaeger, 1959):

$T_{t}(z, t)=\frac{z}{2 \sqrt{\pi \kappa}} \int_{0}^{t} \frac{T_{0}\left(t^{\prime}\right)}{\left(t-t^{\prime}\right)^{3 / 2}} \times \exp \left(\frac{-z^{2}}{4 \kappa\left(t-t^{\prime}\right)}\right) d t^{\prime}$

where the thermal diffusivity $\kappa$ is assumed constant.

For a jump $\Delta T$ in surface temperature at time $t$ before present, the temperature perturbation is given by:

$T(z)=\Delta T \times \operatorname{erfc} \frac{z}{2 \sqrt{\kappa t}}$

If temperature increases linearly from 0 at time $t$ before present to $\Delta T$ now, the surface temperature perturbation is given by:

$T(z)=\Delta T\left(\left(1+\frac{z^{2}}{2 \kappa t}\right) \times \operatorname{erfc} \frac{z}{2 \sqrt{\kappa t}}+\frac{z}{2 \sqrt{\kappa t}} \times \exp \frac{z^{2}}{4 \kappa t}\right)$

For a constant change in surface heat flux $\Delta q$ starting at time $t$ before present, the temperature perturbation is (Carslaw and Jaeger, 1959):

$T(z)=\frac{2 \Delta q}{\lambda}\left(\left(\frac{\kappa t}{\pi}\right)^{1 / 2} \times \exp \frac{-z^{2}}{4 \kappa t}-\frac{z}{2} \times \operatorname{erfc} \frac{z}{2 \sqrt{\kappa t}}\right)$ 


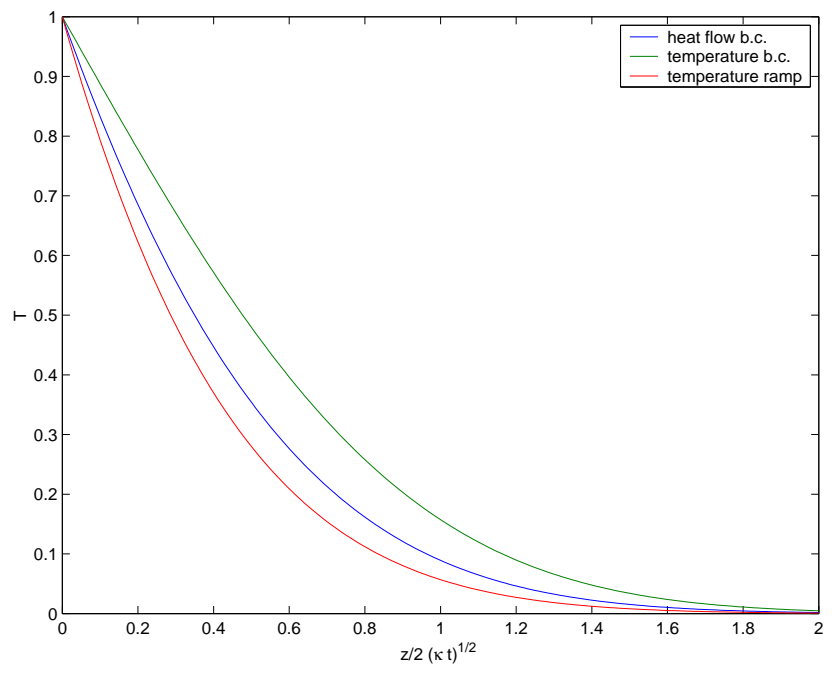

Fig. 2. Comparison of temperature profiles corresponding to different surface boundary conditions: Constant temperature, constant heat flux, and linearly increasing temperature.

and, in particular, the change in surface temperature is given by:

$T(z=0)=\frac{2 \Delta q}{\lambda}\left(\frac{\kappa t}{\pi}\right)^{1 / 2}$

Such a boundary condition was used by Beltrami (2001).

Figure 2 shows the temperature profiles for three different surface boundary conditions leading the same present surface temperature. As one would expect, warming is more rapid after a jump in surface temperature than after a jump in surface heat flow. This is well known, but the point is that the reconstructed history depends on the boundary condition, which is poorly understood. For instance, using a heat flow boundary condition might lead to underestimating the time when the change in surface temperature conditions occurred.

It is possible to account for variations in thermal diffusivity with depth. Formal solutions for the transient temperature in a horizontally layered half space are easily obtained with the Laplace transform (e.g. Carslaw and Jaeger, 1959). It is thus possible to include the variations in thermal diffusivity in the equations but advantages are too small to warrant the additional complications. The "Born approximation" to the general solution of the heat equation for continuously varying physical properties with depth is given in Shen and Beck (1991). Because thermal diffusivity variations are usually small, their effect on the transient temperature profile is a second order perturbation that can safely be neglected in view of all the other sources of error, provided that the average diffusivity is well determined. This does not hold true for the effect of conductivity variations on the steady state temperature profile which must be accounted for.

\subsection{The inverse problem}

For borehole temperature data, the inverse problem consists of determining, from the temperature-depth profile, the reference surface temperature and heat flow, and the ground surface temperature history. Determining the reference heat flow requires knowledge of the thermal conductivity variations, usually measured on core samples. Alternatively, the thermal conductivity structure can be introduced as free model parameters through the thermal resistance vs depth in Eq. (1), but in this case the inverse problem becomes nonlinear.

Generally, the inverse problem can be expressed as an integral equation:

$T(z)=\int_{-\infty}^{0} \Delta T\left(t^{\prime}\right) K\left(z, t^{\prime}\right) d t^{\prime}$

where the kernel $K\left(z, t^{\prime}\right)$ is given in Eq. (2). It turns out that this type of integral equation always describes an ill-posed problem. If $T(z)$ is known approximately, there is no solution to the inverse problem. Furthermore, an approximate solution is useless because the inverse operator is not continuous. The physical meaning of this instability is easy to understand. We can always add to the solution $\Delta T(t)$ a periodic function $N \sin (\omega t)$. Regardless how large $N$, the effect on the temperature profile $T(z)$ can be made arbitrarily small by increasing the frequency $\omega$. In other words, the difference between the exact and the approximate surface temperatures could be arbitrarily large at almost any time. This is paradoxical, but we do take advantage of this property because we are mainly concerned with long period trends. In inverting temperature depth profiles, we can thus safely neglect the daily or the annual cycles although their amplitudes are at least ten times larger than those of the long term trends that we are trying to detect.

\subsection{The inverse problem discretized}

Because the temperature variations of short duration are filtered out of the temperature profile, any parametrization that allows to reproduce the gross features of the surface temperature history could be used. Many different parameterizations have been proposed for the GSTH: a discontinuous function corresponding to the mean surface temperature during $K$ time intervals $\Delta_{k}(k=1, \ldots . N)$, a continuous function varying linearly within $K$ intervals $\Delta_{k}$, a Fourier series, etc.

We shall assume that the GSTH is approximated by a discontinuous function corresponding to the mean surface temperature during $K$ intervals of duration $\Delta_{k}$ (where the $\Delta_{k}$ can be adjusted to the resolution decreasing with time).

For a single temperature profile, the temperature $\Theta_{j}$ measured at depth $z_{j}$ can be written as:

$\Theta_{j}=A_{j l} X_{l}$ 
where $\Theta_{j}$ is the measured temperature at depth $z_{j}$ corrected for the heat production between the surface and that depth, $X_{l}$ is a vector containing the unknowns $\left\{T_{0}, q_{0}, T_{1}, \ldots, T_{K}\right\}$, and $A_{j l}$ is a matrix containing 1 in the first column and the thermal resistances to depth $z_{j}, R\left(z_{j}\right)$ in the second column. In columns 3 to $K+2$ the elements $A_{j, k+2}$ are obtained by calculating the differences between error functions at times $t_{k}$ and $t_{k-1}$ for depth $z_{j}$ :

$A_{j, k+2}=\operatorname{erfc}\left(\frac{z_{j}}{2 \sqrt{\kappa t_{k}}}\right)-\operatorname{erfc}\left(\frac{z_{j}}{2 \sqrt{\kappa t_{k-1}}}\right)$

where $\kappa$ is the thermal diffusivity. The other parameterizations mentioned above would yield a system of equations with the same structure.

Because the meteorological trends appear correlated over distances of $\approx 500 \mathrm{~km}$ (Jones et al., 1986; Hansen and Lebedeff, 1987), boreholes from different sites in the same region may have recorded identical GSTH. If this is indeed the case, it is possible to derive this common GSTH from simultaneous inversion of all the temperature profiles that have recorded seemingly consistent climatic signals. For $I$ boreholes, the unknown parameters are the $I$ surface temperatures and heat flow values and the $K$ parameters of the ground temperature history. The data are all the temperature measurements from all the boreholes. If $N_{i}$ is the number of temperature measurements at borehole $i$, the matrix has $N_{1}+N_{2}+\ldots+N_{I}$ rows and $K+2 \times I$ columns. The first $N_{1}$ elements of the first column equal 1 and all the others equal 0 ; the following $N_{2}$ elements in the second column are 1 and all the other elements are 0 , and so on. The following $I$ columns contain the thermal resistances to depth $z_{j}$ in borehole $i$. Finally, the $K$ last rows contain the differences between error functions at times $t_{k}$ and $t_{k-1}$ for every depth and every borehole. The resulting equations can be written as (Clauser and Mareschal, 1995):

$$
\left[\begin{array}{c}
\boldsymbol{\theta}^{(\mathbf{1})} \\
\boldsymbol{\theta}^{(\mathbf{2})} \\
\ldots \\
\boldsymbol{\theta}^{(\boldsymbol{I})}
\end{array}\right]=\left[\begin{array}{ccccccccc}
1 & 0 & \ldots & 0 & \mathbf{R}^{(\mathbf{1})} & 0 & \ldots & 0 & \mathbf{A}^{(\mathbf{1})} \\
0 & 1 & \ldots & 0 & 0 & \mathbf{R}^{(\mathbf{2})} & \ldots & 0 & \mathbf{A}^{(\mathbf{2})} \\
\ldots & \ldots & \ldots & \ldots & \ldots & \ldots & \ldots & \ldots & \ldots \\
0 & 0 & \ldots & 1 & 0 & 0 & \ldots & \mathbf{R}^{(\mathbf{I})} & \mathbf{A}^{(\mathbf{I})}
\end{array}\right] \times\left[\begin{array}{c}
T_{0}^{(1)} \\
T_{0}^{(2)} \\
\ldots \\
T_{0}^{(I)} \\
q_{0}^{(1)} \\
q_{0}^{(2)} \\
\ldots \\
q_{0}^{(I)} \\
\boldsymbol{T}
\end{array}\right]
$$

where $\theta^{(i)}$ denote the vectors of temperature data for borehole $i$ and $\mathbf{R}^{(\mathbf{i})}$ denote the vectors containing thermal resistance to each depth in borehole $i$; the elements of the matrix $\mathbf{A}^{(\mathbf{i})}$ are the differences between error functions at time $t_{k}$ and $t_{k-1}$ for each depth of borehole $i$. Thermal diffusivity is usually assumed constant within each borehole but varies between boreholes. The unknown parameters are the $I$ reference surface temperatures $T_{0}^{(i)}$, the $I$ reference heat flows $q_{0}^{(i)}$, and the $K$ parameters of the common ground surface temperature history contained in the vector $\boldsymbol{T}$. The reference temperature and heat flow determined by this procedure are only relative to the ground surface temperature history that is reconstructed. In Canada where the last glaciation and the glacial retreat are well documented, an adjustment to the heat flow is always made to account for the glacial interglacial history (e.g., Jessop, 1971).

\subsubsection{Regularization by singular value decomposition}

The system of $N$ linear equations defined by Eqs. (8) and (10) must be solved for the $M=K+2 \times I$ unknown parameters. In general, the system is both underdetermined and overdetermined, and it is unstable. If the system of equations $A x=b$ is mixed-determined, a generalized solution can be obtained by the singular value decomposition (SVD) (Lanczos, 1961; Press et al., 1992). It involves the decomposition of the $(N \times M)$ matrix $\mathbf{A}$ as follows:

$\mathbf{A}=U \Lambda V^{T}$

where superscript $T$ denotes the transpose of a matrix. The matrix $\mathbf{U}$ is an $(\mathbf{N} \times \mathbf{N})$ orthonormal matrix (i.e. a rotation matrix) in data space, $\mathbf{V}$ is an $(\mathbf{M} \times \mathbf{M})$ orthonormal matrix in parameter space, and $\boldsymbol{\Lambda}$ is an $(\mathbf{N} \times \mathbf{M})$ diagonal matrix; the only nonzero elements are the $L$ "singular values" $\lambda_{l}$ on the diagonal, $L \leq \min (N, M)$. The generalized solution is given by

$x=\mathbf{V} \Lambda^{-1} \mathbf{U}^{T} b$

where the $(\mathbf{M} \times \mathbf{N})$ matrix $\boldsymbol{\Lambda}^{-1}$ is a diagonal matrix with the $L$ elements $1 / \lambda_{l}$ on the diagonal (for $\lambda_{l} \rightleftharpoons 0$ ) completed with zeros. The instability of the inversion results from the existence of very small singular values. In practice, this problem can be alleviated either by retaining only the $P \leq L$ singular values larger than a given "cutoff" or by damping the reciprocals of the smaller singular values. The damping is done by replacing the reciprocals of the smaller singular values $\lambda_{l}$ by

$\frac{1}{\lambda_{l}} \rightarrow \frac{\lambda_{l}}{\lambda_{l}^{2}+\epsilon^{2}}$

where $\epsilon$ will be referred to as damping or regularization parameter. The impact of noise can be reduced by selecting a higher value $\epsilon$, which, however, decreases the resolution (Beltrami et al., 1997). For borehole temperature data, the value of $\epsilon$ in joint inversions ranges between 0.1 and 0.3. The damping parameter is usually slightly higher than the singular value cutoff $(\approx 0.05)$. In practice, we make some assumption on the regularity of the solution and select the damping parameter accordingly (Parker, 1994). The procedure consists of selecting a relatively low value of the parameter, and examining the resulting GSTH; if oscillations of large amplitude appear in the solution, the value of the damping parameter is increased until these oscillations are attenuated (Clauser and Mareschal, 1995). Oscillations in the 
very recent past are the result of the structure of the eigenvectors in model space and are difficult to eliminate altogether with a sharp cutoff. Although there is no compelling argument to prefer one method over the other, damping usually gives smoother results than the sharp cutoff. In particular, a proper selection of the damping parameter for individual inversions will reduce the amplitude of the oscillations during the 20th century to a level comparable to that found in the meteorological records.

\section{Description of the data}

The borehole temperature profiles used in this study were obtained by researchers at GEOTOP and at the Institut de Physique du Globe de Paris (IPGP) over the past twenty years. The measurements were made for determining heat flow in the Canadian Shield and are described in a series of papers (Pinet et al., 1991; Mareschal et al., 2000, 2005; Perry et al., 2006).

This study separates in three regions all the borehole temperature depth profiles logged for heat flow determination in the Canadian Shield by the GEOTOP-IPGP team over the past 20 years (Fig. 1). In order to give the same weight to deep boreholes in the simultaneous inversion, all boreholes deeper than $550 \mathrm{~m}$ were truncated to that depth. This procedure avoids biasing the inversion toward the GSTH recorded by deeper holes (Beltrami and Mareschal, 1995). Because the LIA affects the temperature profiles to $\approx 400 \mathrm{~m}$ depth, the depth selected allows to detect the variations in ground surface temperature of the past 500 years. Also, since shallow boreholes are very difficult to reduce with accuracy and to invert, they could affect the simultaneous inversions. Therefore, all boreholes shallower than approximately $350 \mathrm{~m}$ were automatically rejected. Between 1100 and 1900 A.D., all the proxy data indicate that the variations in ground surface temperature remained relatively small. Their effect on the temperature profile beneath $300 \mathrm{~m}$ is sufficiently small that the reference heat flow and surface temperature (relative to that period) are well determined. This does not hold for the glacial-interglacial cycle which affects the profile to depths in excess of $2500 \mathrm{~m}$ (Hartman and Rath, 2005). In Canada, an adjustment accounting for this cycle is routinely made to determine the surface heat flow.

The boreholes located in central Canada between the provinces of Saskatchewan and Manitoba were logged between 1993 and 1999. Table 1 shows the location of all these boreholes with their depth and a remark explaining if it was retained for inversion or the reason why it was rejected.

The second region selected in this study covers a large part of north-western Ontario. Most of the boreholes in this region were logged between 2000 and 2005 and their locations, depths and remarks are shown in Table 2.

The third region covers the eastern part of Ontario and the western part Quebec. The temperatures measurements were made for heat flow determination between 1987 and 1993 . The location, depth and remarks for each borehole are given in Table 3. Because at that time the objective of the measurement was not the study of climate change, the surface conditions were not sufficiently documented to select boreholes suitable for inversion. Only the shallowest boreholes have been eliminated from the study. Analysis of this dataset will allow to compare the trends in three different regions when all the measured boreholes are retained for inversion.

For all profiles, temperature measurements are made at $10 \mathrm{~m}$ intervals using an electrical cable and a probe equipped with a thermistor. The precision of these measurements is of the order of $0.002 \mathrm{~K}$ and the overall accuracy is better than $0.02 \mathrm{~K}$. The GEOTOP-IPGP research team is equipped with several cables ranging from $600 \mathrm{~m}$ to $2.3 \mathrm{~km}$ and with probes capable of measuring temperatures in the range between -15 to 50 degrees Celsius.

For each borehole, core samples were collected to measure their thermal conductivity. Usually, the core is sampled every $80-100 \mathrm{~m}$, and wherever important changes in lithology occur. Thermal conductivity is determined by the method of divided bars (Misener and Beck, 1960). Heat generation is also determined for the heat flow studies. Heat generation is usually low in the Canadian Shield and has little effect on the shallow part of the temperature profiles, and it can be ignored except for very deep boreholes.

Each profile was carefully examined and when necessary erratic data points in the shallow part of the profile were removed. These erratic values are caused by the probe not equilibrating with the groundwater or by water movement near the ground surface. A test was performed to verify that this removal does not affect the GSTH. A synthetic temperature depth profile was inverted using first the complete profile, then the same profile without the first $30 \mathrm{~m}$, and finally the same profile without the first $60 \mathrm{~m}$. The results showed almost no difference in the GSTH between the complete and the profile truncated above $30 \mathrm{~m}$, while the resolution of the recent past decreases for GSTH obtained from the profile truncated above $60 \mathrm{~m}$. This test shows that the removal of one or two data points in the topmost $20 \mathrm{~m}$ of many boreholes does not strongly affect the recent part of the GSTH.

\section{Results}

\subsection{Tests with synthetic data}

The SVD method for simultaneous inversions has been thoroughly tested for regional GSTH by using multiple series of 84 synthetic temperature depth profiles containing a ground surface temperature history signal of 600 years similar to those appearing in recent publications for central and eastern Canada (Guillou-Frottier et al., 1998; Gosselin and Mareschal, 2003; Beltrami and Mareschal, 1992). Each synthetic temperature depth profile had random noise added to 
Table 1. Saskatchewan-Manitoba temperature profiles. For each borehole deeper than $300 \mathrm{~m}$, we give the location, the log identification number, the geographic coordinates, the vertical depth measured $(\Delta h)$ and either that it was selected or the identified cause of non climatic perturbation.

\begin{tabular}{|c|c|c|c|c|c|}
\hline Site & Log i.d. & Latitude & Longitude & $\Delta \mathrm{h}, \mathrm{m}$ & Selection Comment \\
\hline Wabowden & 9301 & $54^{\circ} 52^{\prime} 29^{\prime \prime}$ & $98^{\circ} 38^{\prime} 39^{\prime \prime}$ & 810 & Lake \\
\hline Wabowden & 9302 & $54^{\circ} 52^{\prime} 29^{\prime \prime}$ & $98^{\circ} 38^{\prime} 39^{\prime \prime}$ & 810 & Lake \\
\hline Flin Flon & 9303 & $54^{\circ} 47^{\prime} 00^{\prime \prime}$ & $101^{\circ} 53^{\prime} 00^{\prime \prime}$ & 507 & Steep topography \\
\hline Flin Flon & 9304 & $54^{\circ} 47^{\prime} 14^{\prime \prime}$ & $101^{\circ} 53^{\prime} 10^{\prime \prime}$ & 542 & Steep topography \\
\hline Schist Lake & 9305 & $54^{\circ} 43^{\prime} 11^{\prime \prime}$ & $101^{\circ} 49^{\prime} 57^{\prime \prime}$ & 870 & Lake \\
\hline Reed Lake & 9306 & $54^{\circ} 34^{\prime} 15^{\prime \prime}$ & $100^{\circ} 22^{\prime} 50^{\prime \prime}$ & 433 & Lake \\
\hline Flin Flon & 9307 & $54^{\circ} 47^{\prime} 14^{\prime \prime}$ & $101^{\circ} 53^{\prime} 17^{\prime \prime}$ & 577 & Steep topography \\
\hline Snow Lake & 9308 & $54^{\circ} 52^{\prime} 04^{\prime \prime}$ & $99^{\circ} 58^{\prime} 52^{\prime \prime}$ & 645 & Selected for GSTH \\
\hline Snow Lake & 9309 & $54^{\circ} 51^{\prime} 16^{\prime \prime}$ & $99^{\circ} 57^{\prime} 15^{\prime \prime}$ & 686 & Selected for GSTH \\
\hline Birchtree Mine & 9405 & $55^{\circ} 41^{\prime} 59^{\prime \prime}$ & $97^{\circ} 53^{\prime} 50^{\prime \prime}$ & 521 & Refraction \\
\hline Thompson Station & 9407 & $55^{\circ} 44^{\prime} 25^{\prime \prime}$ & $97^{\circ} 49^{\prime} 22^{\prime \prime}$ & 991 & Refraction \\
\hline Moak Lake & 9408 & $55^{\circ} 54^{\prime} 21^{\prime \prime}$ & $97^{\circ} 40^{\prime} 06^{\prime \prime}$ & 267 & Selected for GSTH \\
\hline Moak Lake & 9409 & $55^{\circ} 53^{\prime} 53^{\prime \prime}$ & $97^{\circ} 40^{\prime} 41^{\prime \prime}$ & 470 & Selected for GSTH \\
\hline Pipe Mine & 9410 & $55^{\circ} 29^{\prime} 17^{\prime \prime}$ & $98^{\circ} 07^{\prime} 50^{\prime \prime}$ & 386 & Large tree clearing \\
\hline Pipe Mine & 9411 & $55^{\circ} 29^{\prime} 10^{\prime \prime}$ & $98^{\circ} 07^{\prime} 54^{\prime \prime}$ & 840 & Large tree clearing \\
\hline Pipe Mine & 9412 & $55^{\circ} 29^{\prime} 17^{\prime \prime}$ & $98^{\circ} 07^{\prime} 50^{\prime \prime}$ & 938 & Large tree clearing \\
\hline Thompson Station & 9413 & $55^{\circ} 44^{\prime} 46^{\prime \prime}$ & $97^{\circ} 48^{\prime} 48^{\prime \prime}$ & 555 & Refraction \\
\hline Ruttan Mine & 9414 & $56^{\circ} 29^{\prime} 07^{\prime \prime}$ & $99^{\circ} 36^{\prime} 21^{\prime \prime}$ & 415 & Water flow \\
\hline Ruttan Mine & 9415 & $56^{\circ} 28^{\prime} 50^{\prime \prime}$ & $99^{\circ} 37^{\prime} 09^{\prime \prime}$ & 821 & Water flow \\
\hline West Arm & 9501 & $54^{\circ} 38^{\prime} 13^{\prime \prime}$ & $101^{\circ} 50^{\prime} 51^{\prime \prime}$ & 1180 & Steep topography \\
\hline Cormorant Lake & 9502 & $54^{\circ} 12^{\prime} 49^{\prime \prime}$ & $100^{\circ} 13^{\prime} 47^{\prime \prime}$ & 352 & Lake, steep topography \\
\hline Cormorant Lake & 9503 & $54^{\circ} 13^{\prime} 05^{\prime \prime}$ & $100^{\circ} 13^{\prime} 32^{\prime \prime}$ & 290 & Lake, steep topography \\
\hline Bigstone Lake & 9504 & $54^{\circ} 34^{\prime} 31^{\prime \prime}$ & $103^{\circ} 11^{\prime} 59^{\prime \prime}$ & 244 & Lake \\
\hline Tartan Lake & 9505 & $54^{\circ} 51^{\prime} 28^{\prime \prime}$ & $101^{\circ} 44^{\prime} 23^{\prime \prime}$ & 568 & Lake, steep topography \\
\hline Bigstone Lake & 9506 & $54^{\circ} 34^{\prime} 31^{\prime \prime}$ & $101^{\circ} 11^{\prime} 59^{\prime \prime}$ & 616 & Lake \\
\hline Wasekwan Lake & 9514 & $56^{\circ} 44^{\prime} 04^{\prime \prime}$ & $100^{\circ} 57^{\prime} 01^{\prime \prime}$ & 376 & Selected for GSTH \\
\hline Farley Lake & 9516 & $56^{\circ} 34^{\prime} 84^{\prime \prime}$ & $100^{\circ} 26^{\prime} 07^{\prime \prime}$ & 589 & Permafrost \\
\hline Farley Lake & 9517 & $56^{\circ} 34^{\prime} 84^{\prime \prime}$ & $100^{\circ} 26^{\prime} 07^{\prime \prime}$ & 558 & Permafrost \\
\hline Fox Mine & 9519 & $56^{\circ} 37^{\prime} 52^{\prime \prime}$ & $101^{\circ} 38^{\prime} 02^{\prime \prime}$ & 423 & Selected for GSTH \\
\hline Farley Lake & 9520 & $56^{\circ} 54^{\prime} 34^{\prime \prime}$ & $100^{\circ} 26^{\prime} 18^{\prime \prime}$ & 580 & Permafrost \\
\hline Waden Bay & 9601 & $55^{\circ} 17^{\prime} 31^{\prime \prime}$ & $105^{\circ} 01^{\prime} 11^{\prime \prime}$ & 880 & Steep topography, water flow \\
\hline Brabant & 9603 & $56^{\circ} 07^{\prime} 47^{\prime \prime}$ & $103^{\circ} 42^{\prime} 24^{\prime \prime}$ & 570 & Selected for GSTH \\
\hline Brabant & 9604 & $56^{\circ} 07^{\prime} 54^{\prime \prime}$ & $103^{\circ} 42^{\prime} 01^{\prime \prime}$ & 541 & Selected for GSTH \\
\hline Brabant & 9605 & $56^{\circ} 07^{\prime} 51^{\prime \prime}$ & $103^{\circ} 42^{\prime} 16^{\prime \prime}$ & 464 & Selected for GSTH \\
\hline McIlvenna Bay & 9607 & $54^{\circ} 38^{\prime} 16^{\prime \prime}$ & $102^{\circ} 49^{\prime} 42^{\prime \prime}$ & 947 & Lake, steep topography \\
\hline McIlvenna Bay & 9608 & $54^{\circ} 38^{\prime} 09^{\prime \prime}$ & $102^{\circ} 49^{\prime} 42^{\prime \prime}$ & 560 & Lake, steep topography \\
\hline Denare Beach & 9609 & $54^{\circ} 39^{\prime} 29^{\prime \prime}$ & $102^{\circ} 03^{\prime} 31^{\prime \prime}$ & 585 & Steep topography \\
\hline Denare Beach & 9610 & $54^{\circ} 39^{\prime} 28^{\prime \prime}$ & $102^{\circ} 09^{\prime} 27^{\prime \prime}$ & 534 & Steep topography \\
\hline Frances Lake & 9614 & $56^{\circ} 49^{\prime} 38^{\prime \prime}$ & $101^{\circ} 06^{\prime} 08^{\prime \prime}$ & 419 & Lake \\
\hline Frances Lake & 9615 & $56^{\circ} 49^{\prime} 29^{\prime \prime}$ & $101^{\circ} 06^{\prime} 25^{\prime \prime}$ & 437 & Lake \\
\hline McWhirter Lake & 9616 & $56^{\circ} 35^{\prime} 04^{\prime \prime}$ & $101^{\circ} 39^{\prime} 36^{\prime \prime}$ & 383 & Lake \\
\hline Batty Lake & 9617 & $55^{\circ} 09^{\prime} 52^{\prime \prime}$ & $100^{\circ} 45^{\prime} 34^{\prime \prime}$ & 308 & Selected \\
\hline Missinipe & 9618 & $55^{\circ} 44^{\prime} 55^{\prime \prime}$ & $104^{\circ} 33^{\prime} 21^{\prime \prime}$ & 282 & Steep topography \\
\hline Missinipe & 9619 & $55^{\circ} 44^{\prime} 52^{\prime \prime}$ & $104^{\circ} 33^{\prime} 29^{\prime \prime}$ & 257 & Steep topography \\
\hline Missinipe & 9620 & $55^{\circ} 44^{\prime} 48^{\prime \prime}$ & $104^{\circ} 33^{\prime} 25^{\prime \prime}$ & 265 & Steep topography \\
\hline Missinipe & 9621 & $55^{\circ} 44^{\prime} 42^{\prime \prime}$ & $104^{\circ} 33^{\prime} 10^{\prime \prime}$ & 188 & Steep topography \\
\hline Missinipe & 9622 & $55^{\circ} 44^{\prime} 50^{\prime \prime}$ & $104^{\circ} 33^{\prime} 10^{\prime \prime}$ & 247 & Steep topography \\
\hline
\end{tabular}


Table 1. Continued.

\begin{tabular}{|c|c|c|c|c|c|}
\hline Site & Log i.d. & Latitude & Longitude & $\Delta \mathrm{h}, \mathrm{m}$ & Selection Comment \\
\hline Soab Mine & 9701 & $55^{\circ} 11^{\prime} 30^{\prime \prime}$ & $98^{\circ} 24^{\prime} 40^{\prime \prime}$ & 568 & Shallow part of hole not logged \\
\hline Soab Mine & 9702 & $55^{\circ} 10^{\prime} 14^{\prime \prime}$ & $98^{\circ} 27^{\prime} 28^{\prime \prime}$ & 680 & Selected for GSTH \\
\hline Chisel Lake & 9801 & $54^{\circ} 50^{\prime} 44^{\prime \prime}$ & $100^{\circ} 06^{\prime} 35^{\prime \prime}$ & 715 & \\
\hline Chisel Lake & 9802 & $54^{\circ} 50^{\prime} 48^{\prime \prime}$ & $100^{\circ} 06^{\prime} 24^{\prime \prime}$ & 765 & Topography \\
\hline Mystic Lake & 9803 & $54^{\circ} 36^{\prime} 57^{\prime \prime}$ & $101^{\circ} 58^{\prime} 09^{\prime \prime}$ & 291 & Lake \\
\hline Batty Lake (9617) & 9804 & $55^{\circ} 09^{\prime} 52^{\prime \prime}$ & $100^{\circ} 45^{\prime} 34^{\prime \prime}$ & 308 & Selected for GSTH \\
\hline Limestone Bay & 9805 & $54^{\circ} 12^{\prime} 43^{\prime \prime}$ & $100^{\circ} 13^{\prime} 43^{\prime \prime}$ & 145 & Lake \\
\hline Leo Lake & 9806 & $54^{\circ} 47^{\prime} 24^{\prime \prime}$ & $101^{\circ} 34^{\prime} 11^{\prime \prime}$ & 499 & Steep topography \\
\hline Leo Lake & 9807 & $54^{\circ} 47^{\prime} 24^{\prime \prime}$ & $101^{\circ} 34^{\prime} 12^{\prime \prime}$ & 447 & Steep topography \\
\hline Knife Lake & 9808 & $55^{\circ} 52^{\prime} 08^{\prime \prime}$ & $102^{\circ} 44^{\prime} 25^{\prime \prime}$ & 420 & Topography \\
\hline Knife Lake & 9809 & $55^{\circ} 52^{\prime} 17^{\prime \prime}$ & $102^{\circ} 44^{\prime} 13^{\prime \prime}$ & 278 & Too shallow \\
\hline Mystery Lake & 9812 & $55^{\circ} 49^{\prime} 40^{\prime \prime}$ & $97^{\circ} 45^{\prime} 40^{\prime \prime}$ & 898 & Selected for GSTH \\
\hline Mystery Lake & 9813 & $55^{\circ} 49^{\prime} 40^{\prime \prime}$ & $97^{\circ} 46^{\prime} 36^{\prime \prime}$ & 672 & Unstable measurements \\
\hline Pipe Mine & 9814 & $55^{\circ} 29^{\prime} 10^{\prime \prime}$ & $98^{\circ} 07^{\prime} 35^{\prime \prime}$ & 345 & Over-representation \\
\hline Pipe Mine & 9815 & $55^{\circ} 29^{\prime} 10^{\prime \prime}$ & $98^{\circ} 07^{\prime} 42^{\prime \prime}$ & 348 & Over-representation \\
\hline Pipe Mine & 9816 & $55^{\circ} 29^{\prime} 20^{\prime \prime}$ & $98^{\circ} 07^{\prime} 53^{\prime \prime}$ & 380 & Over-representation \\
\hline Pipe Mine & 9817 & $55^{\circ} 29^{\prime} 12^{\prime \prime}$ & $98^{\circ} 07^{\prime} 47^{\prime \prime}$ & 220 & Over-representation \\
\hline Morgan Lake & 9818 & $54^{\circ} 45^{\prime} 34^{\prime \prime}$ & $100^{\circ} 12^{\prime} 23^{\prime \prime}$ & 668 & Lake \\
\hline Morgan Lake & 9819 & $54^{\circ} 45^{\prime} 51^{\prime \prime}$ & $100^{\circ} 12^{\prime} 53^{\prime \prime}$ & 268 & Lake \\
\hline Callinan Mine & 9901 & $54^{\circ} 47^{\prime} 00^{\prime \prime}$ & $101^{\circ} 51^{\prime} 30^{\prime \prime}$ & 606 & Clearing near highway \\
\hline Kississing Lake & 9903 & $55^{\circ} 12^{\prime} 08^{\prime \prime}$ & $101^{\circ} 21^{\prime} 25^{\prime \prime}$ & 380 & Lake \\
\hline Kississing Lake & 9904 & $55^{\circ} 11^{\prime} 58^{\prime \prime}$ & $101^{\circ} 21^{\prime} 34^{\prime \prime}$ & 280 & Lake \\
\hline Kississing Lake & 9905 & $55^{\circ} 11^{\prime} 53^{\prime \prime}$ & $101^{\circ} 21^{\prime} 26^{\prime \prime}$ & 300 & Lake \\
\hline Flin Flon & 9906 & $54^{\circ} 46^{\prime} 23^{\prime \prime}$ & $101^{\circ} 50^{\prime} 15^{\prime \prime}$ & 1418 & Lake and topography \\
\hline Loonehead Lake & 9907 & $54^{\circ} 55^{\prime} 54^{\prime \prime}$ & $100^{\circ} 33^{\prime} 48^{\prime \prime}$ & 523 & Topography \\
\hline Leo Lake & 9909 & $54^{\circ} 47^{\prime} 25^{\prime \prime}$ & $101^{\circ} 34^{\prime} 19^{\prime \prime}$ & 469 & Topography \\
\hline Missinipe (9622) & 9912 & $55^{\circ} 44^{\prime} 48^{\prime \prime}$ & $104^{\circ} 33^{\prime} 10^{\prime \prime}$ & 255 & Steep topography \\
\hline Missinipe & 9913 & $55^{\circ} 44^{\prime} 53^{\prime \prime}$ & $104^{\circ} 33^{\prime} 97^{\prime \prime}$ & 276 & Steep topography \\
\hline Missinipe & 9915 & $55^{\circ} 45^{\prime} 26^{\prime \prime}$ & $104^{\circ} 33^{\prime} 45^{\prime \prime}$ & 255 & Steep topography \\
\hline Missinipe & 9916 & $55^{\circ} 44^{\prime} 48^{\prime \prime}$ & $104^{\circ} 33^{\prime} 25^{\prime \prime}$ & 262 & Steep topography \\
\hline McCollum Lake & 9917 & $56^{\circ} 08^{\prime} 48^{\prime \prime}$ & $103^{\circ} 08^{\prime} 28^{\prime \prime}$ & 225 & Lake, forest fire \\
\hline McCollum Lake & 9918 & $56^{\circ} 09^{\prime} 34^{\prime \prime}$ & $103^{\circ} 06^{\prime} 57^{\prime \prime}$ & 394 & Lake, forest fire \\
\hline McCollum Lake & 9919 & $56^{\circ} 08^{\prime} 55^{\prime \prime}$ & $103^{\circ} 08^{\prime} 35^{\prime \prime}$ & 254 & Lake, forest fire \\
\hline Cluff Lake Mine & 9920 & $58^{\circ} 22^{\prime} 36^{\prime \prime}$ & $109^{\circ} 32^{\prime} 28^{\prime \prime}$ & 330 & Close to open mine pit \\
\hline Shea Creek & 9921 & $58^{\circ} 13^{\prime} 46^{\prime \prime}$ & $109^{\circ} 31^{\prime} 05^{\prime \prime}$ & 250 & Water flow \\
\hline Shea Creek & 9922 & $58^{\circ} 13^{\prime} 43^{\prime \prime}$ & $109^{\circ} 31^{\prime} 05^{\prime \prime}$ & 730 & Water flow \\
\hline Shea Creek & 9923 & $58^{\circ} 13^{\prime} 49^{\prime \prime}$ & $109^{\circ} 31^{\prime} 12^{\prime \prime}$ & 400 & Water flow \\
\hline Pipe Mine & 0015 & $55^{\circ} 29^{\prime} 17^{\prime \prime}$ & $98^{\circ} 07^{\prime} 50^{\prime \prime}$ & 377 & Over-representation \\
\hline Moak Lake & 0016 & $55^{\circ} 55^{\prime} 32^{\prime \prime}$ & $97^{\circ} 37^{\prime} 09^{\prime \prime}$ & 860 & Large tree clearing \\
\hline Owl & 0017 & $55^{\circ} 40^{\prime} 17^{\prime \prime}$ & $97^{\circ} 51^{\prime} 35^{\prime \prime}$ & 916 & Selected for GSTH \\
\hline Barbara Lake & 0018 & $56^{\circ} 53^{\prime} 20^{\prime \prime}$ & $101^{\circ} 04^{\prime} 16^{\prime \prime}$ & 385 & Lake \\
\hline Barbara Lake & 0019 & $56^{\circ} 53^{\prime} 26^{\prime \prime}$ & $101^{\circ} 04^{\prime} 55^{\prime \prime}$ & 672 & Lake \\
\hline Pipe Mine & 0020 & $55^{\circ} 29^{\prime} 16^{\prime \prime}$ & $98^{\circ} 08^{\prime} 11^{\prime \prime}$ & 326 & Over-representation \\
\hline Pipe Mine & 0021 & $55^{\circ} 29^{\prime} 09^{\prime \prime}$ & $98^{\circ} 07^{\prime} 54^{\prime \prime}$ & 343 & Over-representation \\
\hline Pipe Mine & 0022 & $55^{\circ} 29^{\prime} 30^{\prime \prime}$ & $98^{\circ} 07^{\prime} 51^{\prime \prime}$ & 375 & Over-representation \\
\hline Pipe Mine (9815) & 0114 & $55^{\circ} 29^{\prime} 10^{\prime \prime}$ & $98^{\circ} 07^{\prime} 42^{\prime \prime}$ & 1610 & Over-representation \\
\hline Pipe Mine & 0115 & $55^{\circ} 29^{\prime} 20^{\prime \prime}$ & $98^{\circ} 07^{\prime} 54^{\prime \prime}$ & 335 & Over-representation \\
\hline Owl & 0116 & $55^{\circ} 40^{\prime} 17^{\prime \prime}$ & $97^{\circ} 51^{\prime} 35^{\prime \prime}$ & 1568 & Same as 0017 \\
\hline
\end{tabular}


Table 2. Northwestern Ontario Sites. For each borehole deeper than $300 \mathrm{~m}$, we give the location, the log identification number, the geographic coordinates, the vertical depth measured $(\Delta h)$ and either that it was selected or the identified cause of non climatic perturbation.

\begin{tabular}{|c|c|c|c|c|c|}
\hline Site & Log i.d. & Longitude & Latitude & $\Delta \mathrm{h}, \mathrm{m}$ & Selection Comment \\
\hline Red Lake & 0001 & $51^{\circ} 00^{\prime} 47^{\prime \prime}$ & $93^{\circ} 48^{\prime} 50^{\prime \prime}$ & 805 & Selected for GSTH \\
\hline Balmertown & 0002 & $51^{\circ} 09^{\prime} 59^{\prime \prime}$ & $93^{\circ} 42^{\prime} 56^{\prime \prime}$ & 1724 & Selected for GSTH \\
\hline Ben Lake & 0003 & $50^{\circ} 53^{\prime} 26^{\prime \prime}$ & $93^{\circ} 06^{\prime} 26^{\prime \prime}$ & 338 & Selected for GSTH \\
\hline Ben Lake & 0004 & $50^{\circ} 52^{\prime} 43^{\prime \prime}$ & $93^{\circ} 06^{\prime} 15^{\prime \prime}$ & 496 & Selected for GSTH \\
\hline Garnet Lake & 0005 & $50^{\circ} 59^{\prime} 49^{\prime \prime}$ & $92^{\circ} 49^{\prime} 27^{\prime \prime}$ & 925 & Lake \\
\hline Mattabi Mine & 0006 & $49^{\circ} 52^{\prime} 36^{\prime \prime}$ & $90^{\circ} 59^{\prime} 45^{\prime \prime}$ & 653 & Steep topography, rail road, tree clearing \\
\hline Mattabi Mine & 0007 & $49^{\circ} 53^{\prime} 39^{\prime \prime}$ & $90^{\circ} 59^{\prime} 51^{\prime \prime}$ & 896 & Selected for GSTH \\
\hline Lac des Iles & 0008 & $49^{\circ} 10^{\prime} 17^{\prime \prime}$ & $89^{\circ} 36^{\prime} 18^{\prime \prime}$ & 675 & Selected for GSTH \\
\hline Lac des Iles & 0009 & $49^{\circ} 10^{\prime} 19^{\prime \prime}$ & $89^{\circ} 36^{\prime} 19^{\prime \prime}$ & 781 & Topography \\
\hline Thunder Bay South & 0010 & $48^{\circ} 10^{\prime} 40^{\prime \prime}$ & $89^{\circ} 29^{\prime} 04^{\prime \prime}$ & 480 & Steep topography, water flow \\
\hline Thunder Bay South & 0011 & $48^{\circ} 11^{\prime} 44^{\prime \prime}$ & $89^{\circ} 28^{\prime} 58^{\prime \prime}$ & 470 & Steep topography, water flow \\
\hline Geco Mine & 0012 & $49^{\circ} 10^{\prime} 00^{\prime \prime}$ & $85^{\circ} 49^{\prime} 29^{\prime \prime}$ & 956 & Steep topography \\
\hline Geco Mine & 0013 & $49^{\circ} 09^{\prime} 30^{\prime \prime}$ & $85^{\circ} 48^{\prime} 36^{\prime \prime}$ & 1435 & Steep topography \\
\hline Rainy River & 0102 & $48^{\circ} 49^{\prime} 54^{\prime \prime}$ & $94^{\circ} 00^{\prime} 46^{\prime \prime}$ & 723 & Selected for GSTH \\
\hline Cameron Lake & 0104 & $49^{\circ} 17^{\prime} 35^{\prime \prime}$ & $93^{\circ} 43^{\prime} 11^{\prime \prime}$ & 638 & Selected for GSTH \\
\hline Rainy River & 0106 & $48^{\circ} 49^{\prime} 44^{\prime \prime}$ & $94^{\circ} 00^{\prime} 54^{\prime \prime}$ & 460 & Selected for GSTH \\
\hline Thunder Lake & 0107 & $49^{\circ} 45^{\prime} 24^{\prime \prime}$ & $92^{\circ} 36^{\prime} 53^{\prime \prime}$ & 734 & Selected for GSTH \\
\hline Thunder Lake & 0108 & $49^{\circ} 45^{\prime} 27^{\prime \prime}$ & $92^{\circ} 36^{\prime} 36^{\prime \prime}$ & 770 & Selected for GSTH \\
\hline Big Whopper & 0111 & $50^{\circ} 15^{\prime} 49^{\prime \prime}$ & $94^{\circ} 33^{\prime} 57^{\prime \prime}$ & 304 & Too shallow \\
\hline Seagull & 0112 & $49^{\circ} 01^{\prime} 39^{\prime \prime}$ & $88^{\circ} 57^{\prime} 27^{\prime \prime}$ & 800 & Water flow \\
\hline Seagull & 0113 & $49^{\circ} 01^{\prime} 39^{\prime \prime}$ & $88^{\circ} 57^{\prime} 30^{\prime \prime}$ & 890 & Water flow \\
\hline Chukuni River & 0201 & $51^{\circ} 03^{\prime} 03^{\prime \prime}$ & $34^{\circ} 44^{\prime} 02^{\prime \prime}$ & 2028 & Selected for GSTH \\
\hline Abino Point & 0203 & $51^{\circ} 06^{\prime} 16^{\prime \prime}$ & $93^{\circ}$ & 575 & Lake \\
\hline Seagull & 0206 & $49^{\circ} 01^{\prime} 35^{\prime \prime}$ & $88^{\circ} 57^{\prime} 23^{\prime \prime}$ & 800 & Water flow \\
\hline Pigeon River & 0207 & $48^{\circ} 03^{\prime} 13^{\prime \prime}$ & $89^{\circ} 31^{\prime} 36^{\prime \prime}$ & 740 & Noisy data \\
\hline Seagull $*$ & 0208 & $49^{\circ} 01^{\prime} 39^{\prime \prime}$ & $88^{\circ} 57^{\prime} 30^{\prime \prime}$ & 890 & Water flow \\
\hline Samuels Lake & 0209 & $48^{\circ} 37^{\prime} 15^{\prime \prime}$ & $92^{\circ} 05^{\prime} 43^{\prime \prime}$ & 370 & Selected for GSTH \\
\hline Samuels Lake & 0210 & $48^{\circ} 37^{\prime} 16^{\prime \prime}$ & $92^{\circ} 05^{\prime} 47^{\prime \prime}$ & 280 & Lake \\
\hline Lumby Lake & 0301 & $49^{\circ} 02^{\prime} 09^{\prime \prime}$ & $91^{\circ} 18^{\prime} 24^{\prime \prime}$ & 573 & Water flow \\
\hline Lumby Lake & 0302 & $49^{\circ} 02^{\prime} 38^{\prime \prime}$ & $91^{\circ} 18^{\prime} 23^{\prime \prime}$ & 412 & Topography \\
\hline Ardeen Mine & 0303 & $48^{\circ} 32^{\prime} 24^{\prime \prime}$ & $90^{\circ} 46^{\prime} 10^{\prime \prime}$ & 597 & Topography \\
\hline Ardeen Mine & 0304 & $48^{\circ} 32^{\prime} 35^{\prime \prime}$ & $90^{\circ} 46^{\prime} 04^{\prime \prime}$ & 587 & Topography \\
\hline Disraeli & 0305 & $49^{\circ} 07^{\prime} 49^{\prime \prime}$ & $88^{\circ} 58^{\prime} 01^{\prime \prime}$ & 291 & Steep topography \\
\hline Junior Lake & 0306 & $50^{\circ} 22^{\prime} 55^{\prime \prime}$ & $87^{\circ} 56^{\prime} 58^{\prime \prime}$ & 352 & Forest fire \\
\hline Junior Lake & 0307 & $50^{\circ} 22^{\prime} 51^{\prime \prime}$ & $87^{\circ} 56^{\prime} 59^{\prime \prime}$ & 370 & Forest fire \\
\hline Junior Lake & 0308 & $50^{\circ} 22^{\prime} 57^{\prime \prime}$ & $87^{\circ} 57^{\prime} 09^{\prime \prime}$ & 423 & Forest fire \\
\hline Gull River & 0309 & $49^{\circ} 45^{\prime} 07^{\prime \prime}$ & $89^{\circ} 11^{\prime} 16^{\prime \prime}$ & 810 & Selected for GSTH \\
\hline Norwood & 0310 & $50^{\circ} 03^{\prime} 47^{\prime \prime}$ & $89^{\circ} 05^{\prime} 22^{\prime \prime}$ & 390 & Topography, Lake \\
\hline Spruce River & 0311 & $49^{\circ} 11^{\prime} 07^{\prime \prime}$ & $88^{\circ} 52^{\prime} 23^{\prime \prime}$ & 349 & Selected for GSTH \\
\hline Nipigon Bay & 0312 & $48^{\circ} 55^{\prime} 11^{\prime \prime}$ & $87^{\circ} 55^{\prime} 12^{\prime \prime}$ & 423 & Lake \\
\hline
\end{tabular}

* Repeat of 0113 .

it; this noise had approximately the same level we observe in measured data. We verified that varying some parameters of the synthetics (noise level, sampling interval, total depth of the profile, reference gradient and surface temperature) does not affect the GSTH.

Most of the parameters mentioned above had little or no effect on the simultaneous inversions. However, we noticed instabilities when the average of all reference temperatures had a value other than 0 . Large oscillations appeared in the GSTH as well as a jump in surface temperature at the beginning of the history. We carefully examined and interpreted the resolution matrices as showing a spill-over of the reference temperatures to the rest of the matrix when a large number of profiles were simultaneously inverted.

In order to prevent this "spill-over" of the reference temperatures into the solution, it was simply removed by using 
Table 3. Eastern Canada temperature profiles: For each borehole deeper than 300 meters, we give the location, the log identification number, the geographic coordinates, the vertical depth measured $(\Delta \mathrm{h})$ and the reason for not retaining the profile when it was not used. 59 out of the 127 logged boreholes are included in this table.

\begin{tabular}{|c|c|c|c|c|c|}
\hline Site & Log i.d. & Longitude & Latitude & $\Delta \mathrm{h}, \mathrm{m}$ & Selection Comment \\
\hline Évain & 8706 & $48^{\circ} 16^{\prime} 47^{\prime \prime}$ & $79^{\circ} 05^{\prime} 49^{\prime \prime}$ & 590 & \\
\hline Évain & 8707 & $48^{\circ} 16^{\prime} 53^{\prime \prime}$ & $79^{\circ} 05^{\prime} 25^{\prime \prime}$ & 590 & \\
\hline Val d'Or & 8708 & $48^{\circ} 05^{\prime} 57^{\prime \prime}$ & $77^{\circ} 33^{\prime} 33^{\prime \prime}$ & 357 & \\
\hline Val d'Or & 8709 & $48^{\circ} 05^{\prime} 49^{\prime \prime}$ & $77^{\circ} 33^{\prime} 22^{\prime \prime}$ & 335 & \\
\hline Mont Vallières de St-Réal & 8719 & $48^{\circ} 49^{\prime} 50^{\prime \prime}$ & $65^{\circ} 57^{\prime} 35^{\prime \prime}$ & 599 & Topography \\
\hline Mont Vallières de St-Réal & 8720 & $48^{\circ} 49^{\prime} 53^{\prime \prime}$ & $66^{\circ} 00^{\prime} 48^{\prime \prime}$ & 600 & Topography \\
\hline Mont Vallières de St-Réal & 8721 & $48^{\circ} 49^{\prime} 17^{\prime \prime}$ & $66^{\circ} 01^{\prime} 17^{\prime \prime}$ & 500 & Topography \\
\hline Dôme de Lemieux & 8723 & $48^{\circ} 48^{\prime} 49^{\prime \prime}$ & $66^{\circ} 07^{\prime} 48^{\prime \prime}$ & 520 & Topography \\
\hline Dôme de Lemieux & 8724 & $48^{\circ} 47^{\prime} 23^{\prime \prime}$ & $66^{\circ} 10^{\prime} 54^{\prime \prime}$ & 571 & Topography \\
\hline Dôme de Lemieux & 8725 & $48^{\circ} 47^{\prime} 08^{\prime \prime}$ & $66^{\circ} 08^{\prime} 55^{\prime \prime}$ & 350 & Topography \\
\hline Desmaraisville & 8736 & $49^{\circ} 36^{\prime} 54^{\prime \prime}$ & $75^{\circ} 50^{\prime} 50^{\prime \prime}$ & 335 & Topmost $50 \mathrm{~m}$ missing \\
\hline Desmaraisville & 8740 & $49^{\circ} 37^{\prime} 11^{\prime \prime}$ & $75^{\circ} 52^{\prime} 12^{\prime \prime}$ & 306 & \\
\hline Chapais & 8742 & $49^{\circ} 47^{\prime} 19^{\prime \prime}$ & $74^{\circ} 48^{\prime} 34^{\prime \prime}$ & 519 & \\
\hline Chapais & 8743 & $49^{\circ} 47^{\prime} 49^{\prime \prime}$ & $74^{\circ} 48^{\prime} 33^{\prime \prime}$ & 504 & \\
\hline Matagami & 8744 & $49^{\circ} 42^{\prime} 58^{\prime \prime}$ & $77^{\circ} 44^{\prime} 03^{\prime \prime}$ & 600 & \\
\hline Matagami & 8745 & $49^{\circ} 42^{\prime} 48^{\prime \prime}$ & $77^{\circ} 44^{\prime} 03^{\prime \prime}$ & 600 & \\
\hline Matagami & 8746 & $49^{\circ} 42^{\prime} 56^{\prime \prime}$ & $77^{\circ} 44^{\prime} 20^{\prime \prime}$ & 600 & \\
\hline Renfrew & 8801 & $45^{\circ} 25^{\prime} 23^{\prime \prime}$ & $76^{\circ} 42^{\prime} 17^{\prime \prime}$ & 372 & Noisy \\
\hline Belleterre & 8810 & $47^{\circ} 24^{\prime} 03^{\prime \prime}$ & $78^{\circ} 42^{\prime} 41^{\prime \prime}$ & 420 & \\
\hline Belleterre & 8811 & $47^{\circ} 24^{\prime} 06^{\prime \prime}$ & $78^{\circ} 42^{\prime} 37^{\prime \prime}$ & 387 & \\
\hline Belleterre & 8812 & $47^{\circ} 24^{\prime} 08^{\prime \prime}$ & $78^{\circ} 42^{\prime} 43^{\prime \prime}$ & 357 & \\
\hline Belleterre & 8813 & $47^{\circ} 24^{\prime} 08^{\prime \prime}$ & $78^{\circ} 42^{\prime} 46^{\prime \prime}$ & 389 & \\
\hline Madoc & 8814 & $44^{\circ} 30^{\prime} 14^{\prime \prime}$ & $77^{\circ} 27^{\prime} 06^{\prime \prime}$ & 330 & Measurements in open pit \\
\hline Cordova Mine & 8820 & $44^{\circ} 32^{\prime} 00^{\prime \prime}$ & $77^{\circ} 47^{\prime} 16^{\prime \prime}$ & 377 & \\
\hline Darlington & 8901 & $43^{\circ} 52^{\prime} 05^{\prime \prime}$ & $78^{\circ} 43^{\prime} 00^{\prime \prime}$ & 300 & Industrial site \\
\hline Snowdon & 8905 & $44^{\circ} 51^{\prime} 24^{\prime \prime}$ & $78^{\circ} 30^{\prime} 02^{\prime \prime}$ & 318 & Water flow \\
\hline Snowdon & 8907 & $44^{\circ} 51^{\prime} 27^{\prime \prime}$ & $78^{\circ} 30^{\prime} 12^{\prime \prime}$ & 300 & Water flow \\
\hline Limerick & 8910 & $44^{\circ} 52^{\prime} 15^{\prime \prime}$ & $77^{\circ} 43^{\prime} 18^{\prime \prime}$ & 340 & Noisy \\
\hline Limerick & 8911 & $44^{\circ} 52^{\prime} 17^{\prime \prime}$ & $77^{\circ} 43^{\prime} 25^{\prime \prime}$ & 425 & Top $80 \mathrm{~m}$ missing \\
\hline
\end{tabular}

the reduced temperature profiles (i.e. the difference between the observed and reference profiles). When properly reduced, a profile only shows the perturbations to the steady-state temperature in the borehole without any information on the reference temperature or gradient. Further tests with series of synthetic temperature depth profiles showed that GSTHs obtained from reduced profiles accurately recover the input.

Although no problems were identified when using observed temperature profiles for individual inversions or simultaneous inversions using a limited number of profiles, it is recommended to use reduced profiles when inverting simultaneously many profiles.

4.2 Study with real data: selection of profiles and interpretation

\subsubsection{Manitoba-Saskatchewan}

The first data set analyzed was from the SaskatchewanManitoba region (Fig. 1), consisting of 106 boreholes logged between 1993 and 1999. First, all boreholes shallower than approximately $200 \mathrm{~m}$ were eliminated. This was necessary because the reference gradient for such shallow profiles is too poorly constrained for the profiles to be reduced. Also these shallow profiles do not provide the desired time window for this study. Another 3 boreholes (9903, 9904 and 9905) from the Kississing Lake site were removed from the dataset because the lake effect was so overwhelming that it overshadowed the signal of the other profiles. This limited to 73 the number of usable boreholes for the regional study in Saskatchewan-Manitoba. From these 73 boreholes, only 13 were considered affected by no other surface condition than a temporal change in the ground surface temperatures. Table 1 lists all the boreholes in the region with their characteristics and the non-climatic effects that were noted. The reduced temperature profiles for the entire data set show a lot of variability and seem inconsistent; however, the 13 retained profiles are much more similar and consistent with each other. All the profiles are shown in Fig. 3a. Since most of these 
Table 3. Continued.

\begin{tabular}{|c|c|c|c|c|c|}
\hline Site & Log i.d. & Longitude & Latitude & $\Delta \mathrm{h}, \mathrm{m}$ & Selection Comment \\
\hline Copper Cliff & 8925 & $46^{\circ} 26^{\prime} 24^{\prime \prime}$ & $81^{\circ} 03^{\prime} 56^{\prime \prime}$ & 560 & \\
\hline Copper Cliff & 8926 & $46^{\circ} 26^{\prime \prime \prime}$ & $81^{\circ} 03^{\prime \prime \prime}$ & 600 & \\
\hline Copper Cliff & 8927 & $46^{\circ} 26^{\prime \prime \prime}$ & $81^{\circ} 03^{\prime \prime \prime}$ & 473 & \\
\hline Bourlamaque & 9001 & $48^{\circ} 06^{\prime} 54^{\prime \prime}$ & $77^{\circ} 44^{\prime} 58^{\prime \prime}$ & 417 & \\
\hline Selbaie Mine & 9005 & $49^{\circ} 49^{\prime} 19^{\prime \prime}$ & $78^{\circ} 57^{\prime} 48^{\prime \prime}$ & 387 & Water flow \\
\hline Selbaie Mine & 9006 & $49^{\circ} 48^{\prime} 53^{\prime \prime}$ & $78^{\circ} 57^{\prime} 05^{\prime \prime}$ & 407 & Water flow \\
\hline Selbaie Mine & 9007 & $49^{\circ} 49^{\prime} 02^{\prime \prime}$ & $78^{\circ} 56^{\prime} 40^{\prime \prime}$ & 397 & Water flow \\
\hline Ile Marguerite & 9008 & $49^{\circ} 53^{\prime} 36^{\prime \prime}$ & $74^{\circ} 10^{\prime} 28^{\prime \prime}$ & 593 & Island \\
\hline Ile Marguerite & 9009 & $49^{\circ} 53^{\prime} 55^{\prime \prime}$ & $74^{\circ} 10^{\prime} 12^{\prime \prime}$ & 571 & Island \\
\hline Lac aux Dorés & 9010 & $49^{\circ} 52^{\prime} 50^{\prime \prime}$ & $74^{\circ} 20^{\prime} 00^{\prime \prime}$ & 440 & \\
\hline Lac aux Dorés & 9012 & $49^{\circ} 52^{\prime} 50^{\prime \prime}$ & $74^{\circ} 20^{\prime} 01^{\prime \prime}$ & 317 & \\
\hline La Malbaie & 9013 & $47^{\circ} 41^{\prime} 43^{\prime \prime}$ & $70^{\circ} 05^{\prime} 42^{\prime \prime}$ & 490 & \\
\hline Les Éboulements & 9014 & $47^{\circ} 29^{\prime} 05^{\prime \prime}$ & $70^{\circ} 19^{\prime} 43^{\prime \prime}$ & 430 & Water flow \\
\hline Mine Belmoral & 9101 & $48^{\circ} 07^{\prime} 45^{\prime \prime}$ & $77^{\circ} 34^{\prime} 56^{\prime \prime}$ & 316 & \\
\hline Mine Belmoral & 9103 & $48^{\circ} 08^{\prime} 20^{\prime \prime}$ & $77^{\circ} 35^{\prime} 57^{\prime \prime}$ & 360 & \\
\hline Mine Dumagami & 9105 & $48^{\circ} 15^{\prime} 04^{\prime \prime}$ & $78^{\circ} 26^{\prime} 13^{\prime \prime}$ & 430 & \\
\hline Holloway Lake & 9114 & $48^{\circ} 31^{\prime} 11^{\prime \prime}$ & $79^{\circ} 43^{\prime} 07^{\prime \prime}$ & 420 & \\
\hline Holloway Lake & 9116 & $48^{\circ} 31^{\prime} 13^{\prime \prime}$ & $79^{\circ} 43^{\prime} 16^{\prime \prime}$ & 374 & \\
\hline Lebel-Grevet & 9201 & $49^{\circ} 14^{\prime} 13^{\prime \prime}$ & $76^{\circ} 39^{\prime} 12^{\prime \prime}$ & 681 & \\
\hline Lebel-Grevet & 9202 & $49^{\circ} 14^{\prime} 32^{\prime \prime}$ & $76^{\circ} 39^{\prime} 13^{\prime \prime}$ & 880 & \\
\hline Lebel-Grevet & 9203 & $49^{\circ} 14^{\prime} 40^{\prime \prime}$ & $76^{\circ} 39^{\prime} 12^{\prime \prime}$ & 880 & \\
\hline Boyvinet & 9204 & $49^{\circ} 36^{\prime} 12^{\prime \prime}$ & $75^{\circ} 58^{\prime} 49^{\prime \prime}$ & 511 & \\
\hline Boyvinet & 9205 & $49^{\circ} 35^{\prime} 22^{\prime \prime}$ & $75^{\circ} 59^{\prime} 10^{\prime \prime}$ & 425 & \\
\hline Coniagas & 9206 & $49^{\circ} 29^{\prime} 34^{\prime \prime}$ & $79^{\circ} 10^{\prime} 22^{\prime \prime}$ & 450 & \\
\hline Coniagas & 9207 & $49^{\circ} 29^{\prime} 40^{\prime \prime}$ & $76^{\circ} 10^{\prime} 22^{\prime \prime}$ & 610 & \\
\hline Gamache & 9209 & $49^{\circ} 28^{\prime} 46^{\prime \prime}$ & $74^{\circ} 36^{\prime} 40^{\prime \prime}$ & 486 & \\
\hline Gamache & 9211 & $49^{\circ} 29^{\prime} 02^{\prime \prime}$ & $74^{\circ} 37^{\prime} 04^{\prime \prime}$ & 480 & \\
\hline Barraute & 9212 & $48^{\circ} 31^{\prime} 50^{\prime \prime}$ & $77^{\circ} 41^{\prime} 36^{\prime \prime}$ & 370 & \\
\hline Barraute & 9213 & $48^{\circ} 31^{\prime} 45^{\prime \prime}$ & $77^{\circ} 41^{\prime} 08^{\prime \prime}$ & 640 & \\
\hline Barraute & 9214 & $48^{\circ} 31^{\prime} 50^{\prime \prime}$ & $77^{\circ} 41^{\prime} 26^{\prime \prime}$ & 620 & \\
\hline
\end{tabular}

profiles are affected by non-climatic factors, the variability is considerable, although an overall warming trend is clearly visible and can also be inferred from the average GSTH. If only the 13 unaffected temperature depth profiles are plotted (Fig. 3b), the variability decreases dramatically and not only the amplitude of the recent warming, but the onset of the little ice age (LIA) is also apparent. However it is also worth noting that the average of the reduced temperature profiles of the entire and selected datasets are almost identical.

Unless otherwise noted, the same parametrization was used for all the inversions in this study (i.e. 20 year time steps covering 600 years). Thermal conductivity and diffusivity were assumed constant for all inversions in this paper and heat production values were not taken into consideration.

The 73 temperature depth profiles were inverted simultaneously with the same parametrization and a value for regularization parameter, $\epsilon=0.3$. A larger regularization parameter than for the individual inversions is necessary because the singular values are different and decrease more slowly than those of individual inversions. In order to obtain comparable information between individual and simultaneous inversions, one needs to use approximately the same number of singular values for both. Thus, the cut-off needs to be higher in simultaneous inversions than in individual inversions. The result from the simultaneous inversion was then compared with a simultaneous inversion using only the 13 selected profiles and is shown in Fig. 4.

One of the problems of most inversion techniques is the occurrence of instabilities due to the inversion. Actually, the main difficulty is the proper tradeoff between stability and resolution. In the case of SVD, the instability affects the larger singular values and thus the recent past in the GSTH; it is seen as marked oscillation at 20-40 years before present. In this study, the inconsistencies between the records of various boreholes are causing these instabilities. It casts serious doubt that any conclusion concerning the very recent past can be derived from the simultaneous inversion of noisy records. In the data space, the corresponding eigen vectors sample mostly the shallow part of the profile, which is noisiest, i.e. the most affected by non-climatic surface perturbations. 

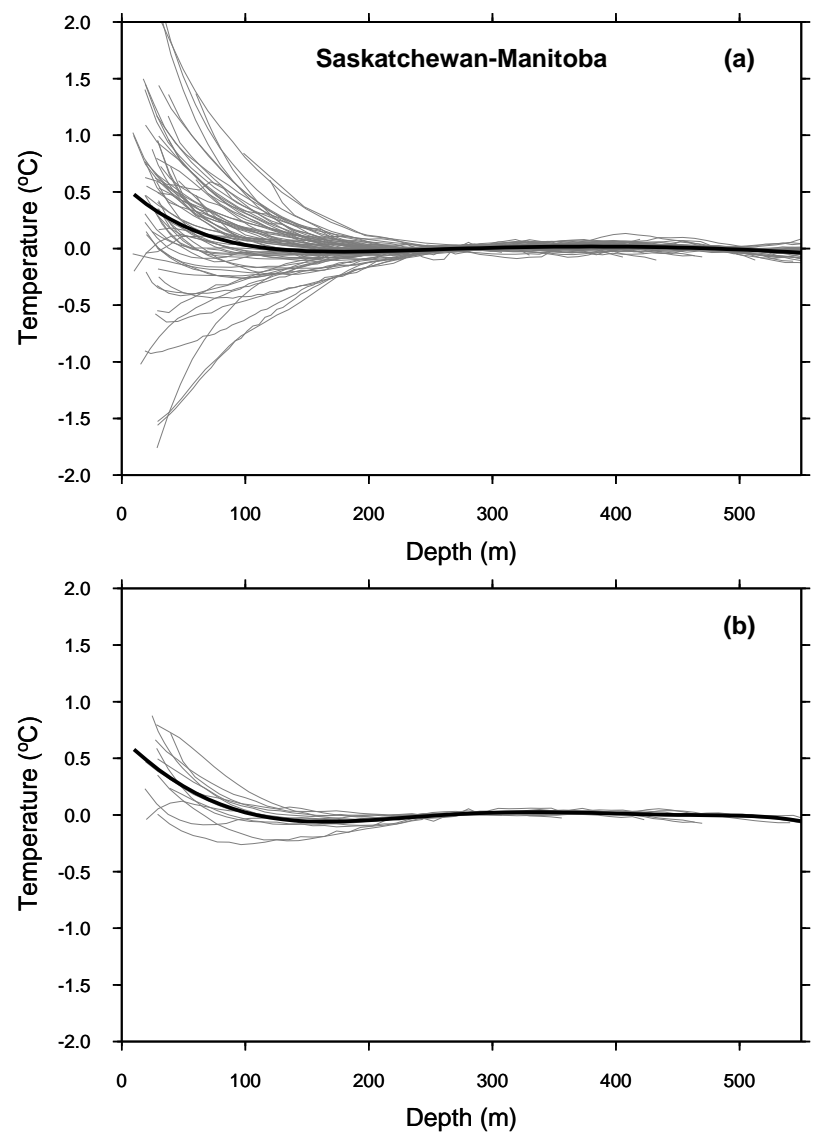

Fig. 3. Reduced temperature-depth profiles measured in northern Manitoba and Saskatchewan: (a) all the profiles recorded; (b) selected profiles not affected by non-climatic surface perturbations. The thick lines represent the average of all the temperature depth profiles.

To alleviate the instability problem and to gain perspective on the resolution of the simultaneous inversions, we calculated the averages of inversion for all the individual profiles from the complete and the selected data-sets. Each profile from the complete data-set of 73 profiles was inverted, using the same regularization parameter for all the profiles $(\epsilon=0.05)$, but adapting the parametrization for the shallow profiles. These individual GSTHs were then averaged in order to obtain a regional GSTH. For the 13 selected profiles, each inversion was optimized by using the smallest regularization parameter possible while preserving the stability of the inversion. There is a major difference between the results obtained from the entire dataset and those from the selected profiles. It concerns the LIA minimum (ca. 1820 A.D.), which is more pronounced in the selected profiles than with the entire dataset. There are two factors explaining that difference of amplitude. First, as mentioned above, the 13 selected profiles were inverted using unique op-

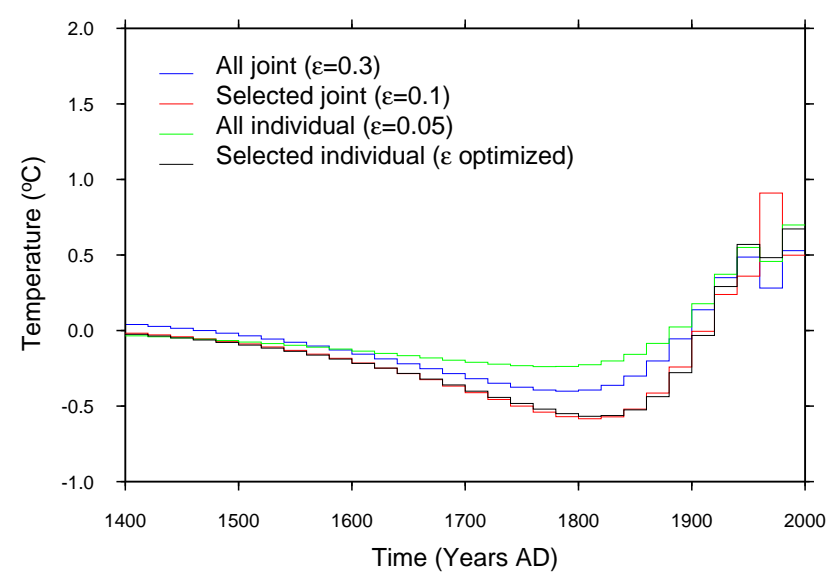

Fig. 4. Comparison of ground-surface temperature histories obtained using different methods for the Saskatchewan-Manitoba region.

timized regularization parameters, meaning each individual inversion was optimized for maximum signal to noise ratio. This optimization is impossible to perform on the complete data-set ( 73 profiles) because the signal is often non-climatic, and the optimization would amplify the noise. Without even amplifying the noise, the many profiles (60 out of of 73) that recorded non-climatic effects will dominate the average and yield near zero temperature perturbation at the time of the LIA. It is noteworthy that individual inversions are performed independently and that there is no constraint to fit a unique model, whereas a simultaneous inversion does have this constraint. In profiles severely affected by non-climatic perturbations, the climatic signal can be taken into consideration by the simultaneous inversion. So in the case of a simple average of individual inversions, the fact that all GSTHs have the same weight means that random non-climatic perturbations will weight heavily on the overall average.

On the other hand, the average of individual inversions has the advantage of being more stable than a joint inversion. Since these instabilities are usually not correlated to the climatic signal, the average of several GSTH will ultimately cancel most of the instabilities and yield a reasonable value in the interval 20-40 years before present (Fig. 4).

\subsubsection{Northwestern Ontario}

The second data-set analyzed for this study was from Northwestern Ontario (Fig. 1). It consists of 56 boreholes logged between 2000 and 2003. All boreholes shallower than approximately $200 \mathrm{~m}$ were eliminated. All the profiles in the dataset are displayed on Fig. 5a. Temperature depth profiles from two more sites were removed from the data-set because of the overwhelming effects they had on the inversions. The profiles (0306, 0307 and 0308) from the Junior Lake site where an important forest fire had occurred a few 

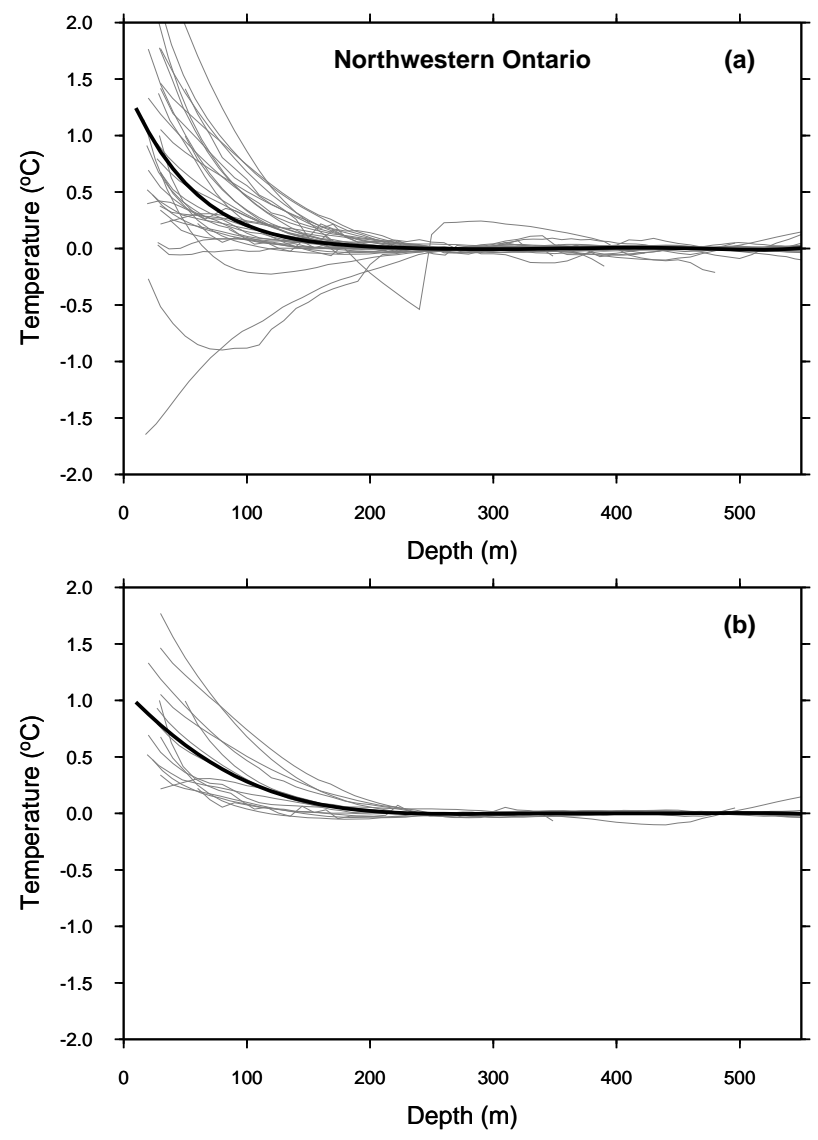

Fig. 5. Reduced temperature-depth profiles measured in northwestern Ontario: (a) all the profiles recorded; (b) selected profiles not affected by non-climatic surface perturbations. The thick lines are the averages of all the profiles.

years before measurements were eliminated. We also eliminated the profiles from Seagull (0112 and 0113) because of the overwhelming effect of water and gas rushing out of an over-pressured zone at depth. The perturbed Seagull profiles are easily identifiable on Fig. 5a. Water was still rushing out of the borehole several weeks after the drilling operations had stopped. The complete dataset of usable boreholes for northwestern Ontario contained 35 boreholes. From this set, 15 were considered unaffected by non-climatic perturbations. The description of the boreholes and the reasons for eliminating some profiles are listed in Table 2. The resulting reduced profiles are shown on Fig. $5 \mathrm{~b}$. The complete dataset includes some very noisy profiles. As in central Canada, the selected profiles exhibit more consistent trends than the complete data set, but the average reduced profiles of both datasets are similar.

As for Manitoba-Saskatchewan, we obtained four different regional GSTHs by inverting jointly and by averaging individual inversions of the complete and of the selected datasets (Fig. 6).

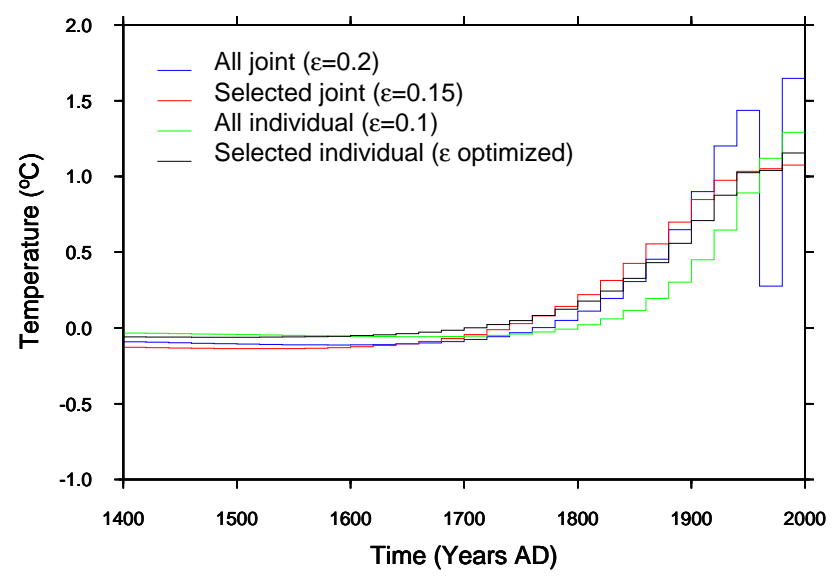

Fig. 6. Comparison of ground-surface temperature histories obtained using different methods for the northwestern Ontario region.

The inversions were performed with the same temporal parametrization as for Manitoba-Saskatchewan (20 year time steps covering 600 years before present). However, because the northwestern Ontario boreholes were generally noisier than those in Saskatchewan-Manitoba a higher value was selected for the regularization parameter of individual inversions $(\epsilon=0.1)$.

The regional GSTH using the complete dataset of 35 temperature depth profiles and the selected dataset of 15 profiles were inverted with a regularization parameter $\epsilon=0.2$ and 0.15 respectively. Despite the high noise level, the regularization parameter is smaller than the one used for ManitobaSaskatchewan region mainly because there are less temperature depth profiles (and thus lower singular values) in the complete data set than in Manitoba-Saskatchewan. On Fig. 6, the GSTHs are reasonably similar until 100 years before present. But the GSTH for the complete dataset is very unstable in the most recent 100 years, showing a serious warming followed by a sudden $1.0 \mathrm{~K}$ drop over a 20 year interval and a $1.25 \mathrm{~K}$ jump in the last 20 year step. This clear non-climatic signal is most likely due to the sum of two factors: 1) an effect of the noisier profiles measured in that region, and 2) the inversion instability.

The average of the individual inversions for the region confirms that this oscillation is due to the instability of the inversion. For the individual inversions, each profile contained in the complete dataset was inverted with a regularization parameter $\epsilon=0.1$; the profiles contained in the selected dataset were all optimized using the best signal to noise ratio possible (smallest regularization parameter). The results are also plotted against the simultaneous inversions on Fig. 6. This suggests that the large oscillation in the simultaneous inversion of the complete dataset is non-climatic, since none of the averages show such a jump. 


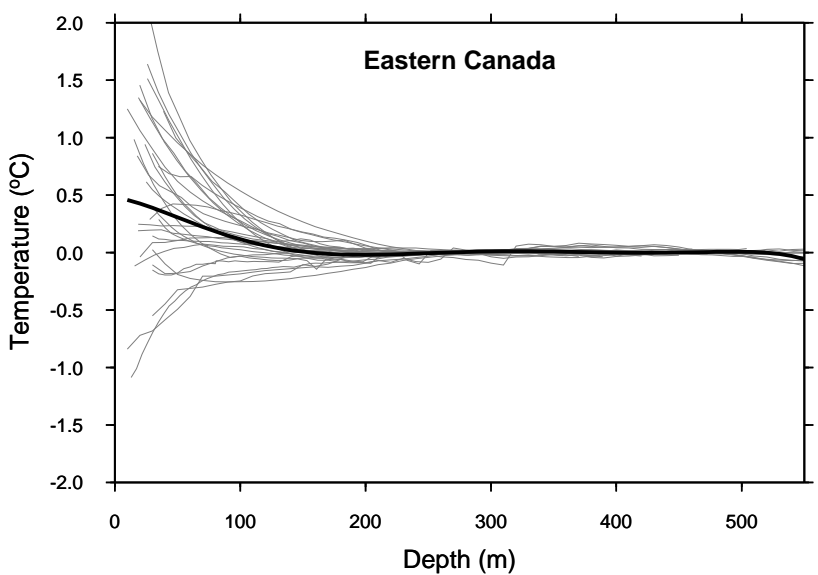

Fig. 7. Reduced temperature profiles measured in eastern Ontario and western Quebec. The thick line represents the average of all the profiles. Surface conditions were not documented to eliminate "noisy" profiles.

The study of western Ontario has also shown that simultaneous inversion of all boreholes in a given region regardless of the site conditions is likely to lead to an erroneous GSTH. A single very perturbed profile has the potential to cause major non-climatic shifts in the final GSTH. This happened with the accidental inclusion of the Seagull site (boreholes \#0112 and 0113) in the data set. The resulting GSTH was very much affected, showing a full degree drop in temperatures with the minimum occurring at the exact time of the LIA minimum (1780 A.D.). This apparent LIA signal was due only to the inclusion of the Seagull site where the temperature profile was extremely perturbed by the gushing out of water and gas that persisted years after drilling. The GSTH without that site contains no LIA signal in western Ontario.

A comparison of the curves obtained by averaging individual inversions of both datasets shows similar GSTHs for the first 300 years and then some divergence in the recent most past, as was observed in the averages of ManitobaSaskatchewan. As was the case in Manitoba-Saskatchewan, the presence of profiles perturbed by random non-climatic effects in the complete dataset tends to bring the average near zero.

The obvious difference between the first two regions is the absence of any LIA signal from the western Ontario datasets. Regardless of noise level or depth, we could not see a LIA cooling period in the GSTH from any of the profiles and are confident that it is missing in that part of Canada.

\subsubsection{Eastern Ontario and Quebec}

The third dataset used for this study contains the oldest measurements taken by the GEOTOP-IPGP research team in Quebec and in eastern Ontario between 1987 and 1992 (Fig. 1). As mentioned before in this paper, these measure-

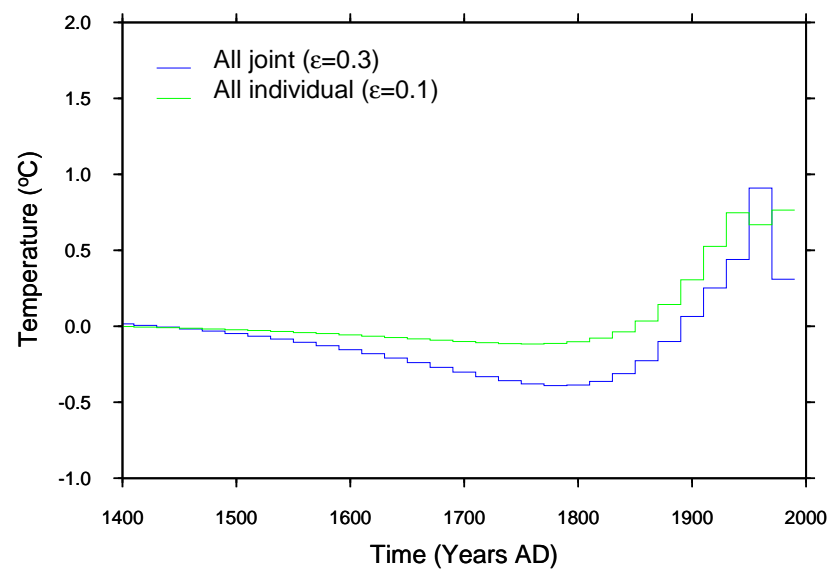

Fig. 8. Comparison of ground-surface temperature histories using two different methods for the eastern Canada region.

ments were taken solely for heat flow studies and there is very little documentation on the actual measurement sites. Because of this lack of information, the analysis of the data from this region was done only on the complete dataset, as it was impossible to identify non-perturbed sites with certainty. Although a total of 137 boreholes had been measured, the complete dataset consists only of 28 usable boreholes because many of these boreholes are too shallow and/or severely perturbed (Table 3 ). The reduced profiles are displayed on Fig. 7. Like in the other two regions, these profiles are quite inconsistent, but the average of all the reduced profiles is not very different from those obtained in the other regions. When we revisited some of these sites, we found out that they were affected by non-climatic perturbations. Some of these 28 boreholes would thus be rejected if we could apply the same strict criteria as in the other two regions.

The 28 temperature depth profiles were all individually inverted using the same parametrization as for the other regions and $\epsilon=0.1$. The regional GSTH for eastern Canada was performed by simultaneously inverting the complete dataset of 28 temperature depth profiles with a regularization parameter $\epsilon=0.3$. As for the other two regions, an average of individual inversions was also performed in order to compare the two methods as well as the effects of potential instabilities. Both curves are plotted in Fig. 8. The difference in amplitude of the LIA minimum (1800 A.D.) between the joint inversion and the average is similar to that observed in central Canada and has the same explanation, the weight of the random nonclimatic perturbations minimizing the GSTH. Therefore, we think that the LIA signal detected in eastern Canada is real. For the recent past (past 60 years), there are differences between the two curves. The joint inversion yields a very unstable GSTH in the very recent past (recent most 60 years). This is another indication that the shallow section of some of the profiles is dominated by noise (i.e. non climatic effects). 
The regional GSTH obtained from the average of individual inversions probably yields the best (i.e. most stable) GSTH for that period, as the instabilities are canceling out in the averaging process.

\section{Discussion}

The study was undertaken to compare different procedures to process and invert a regional GSTH from borehole temperature depth profiles, in particular: (1) Is it better to select boreholes that are not affected by non climatic perturbations, or does the noise from these perturbations cancel out? (2) Is it better to perform a joint inversion of all the temperature depth profiles than to average the results individual inversions? The most important conclusion is that the results obtained by different procedures remain fairly consistent with each other, and the differences between methods are less than the error limits. Provided the inversions are carried out with sufficient care, similar trends will be inferred from all the procedures. This does not mean that they yield identical results. When choosing a particular procedure, we are faced with the standard problem of the tradeoff between resolution and stability of the inversion.

- Whenever possible, i.e. when the sites are well documented, it is much better to select temperature profiles that are not perturbed by non-climatic effects near the surface. Regardless of the method used (joint inversion or averaging of individual inversions), the GSTHs have higher resolution and are more stable than those of the entire dataset.

- Because selected profiles are less noisy than all the profiles from a region and the resolution is determined by the level of noise in the noisiest of the profiles, it is better to invert jointly selected profiles. In other words, the joint inversion of non selected profiles does not improve at all the resolution which is degraded by the level of noise of the noisiest profile. It increases the instability because the eigen vectors in data space that correspond to the large singular values sample the shallow part of the profile that is most affected by the non-climatic perturbations. The resolution is improved by selecting profiles that are not affected by non-climatic signals.

- The average of all the GSTHs from a region has very poor resolution. The individual inversions of all the profiles from a region always yield GSTHs that are very inconsistent with each other. This supports the view that the non-climatic effects are more or less random, but these effects often overwhelm the climatic signal in the individual inversions.

- This study comforted us in the opinion that few good data always yield much better results in terms of resolution and stability than many low quality data. Whenever possible, i.e. when there is a sufficient number of profiles that are well documented, a selection of profiles should be made.

- It is worthwhile to compare the GSTH obtained by averaging individual inversions and by joint inversion of the selected profiles. When profiles are selected, individual inversions yield consistent results. If each individual inversion is optimized, the resolution of the average of the individual inversions is better than that of the joint inversion of the same profiles. Also, the average of the inversions of selected profiles does not show large amplitude oscillations in the very recent past. It appears that averaging individual inversions yields more stable results than the joint inversion of the same profiles. In particular, the amplitude of the oscillations in the averaged GSTH during the 20th century is comparable to that in the meteorological records.

- The comparison of GSTHs using complete and selected temperature depth profiles, show no systematic warming trend due to non-climatic perturbations. If there were systematic warming effects on these perturbed profiles, these would be apparent in the different comparisons of GSTH techniques presented in this paper. However, contrary to the suggestion by Lewis (1998), there does not seem to be any sign of bias in the data and no systematic warmer trend in the GSTH obtained from all the profiles measured in a region than in that obtained from selected profiles.

Determining the ground surface temperature history from borehole temperature profiles in south-central and southeastern Canada has been the object of many studies (Nielsen and Beck, 1989; Beltrami and Mareschal, 1991, 1992; Wang et al., 1994; Guillou-Frottier et al., 1998; Majorowicz et al., 1999; Gosselin and Mareschal, 2003). Our results are consistent with previous results, but because different approaches were used to process the data, our study clarifies the problems of resolution and robustness of the regional GSTH. Our results are consistent with each other but differ in resolution with some trends that are well marked only with some methods.

- Regardless of the method used, there seems to be a warming signal ranging between 0.5 and $1.0 \mathrm{~K}$ over the past 500 years with some regions experiencing different warming rates. The LIA signatures obtained in Manitoba-Saskatchewan and and in eastern Canada are consistent and appear almost synchronous (with very limited time resolution). This suggests that the LIA occurred simultaneously across the central and eastern parts of Canada.

- On the other hand, the LIA is not found in northwestern Ontario, which is located between these two regions. This point was also discussed by Gosselin and 
Mareschal (2003). Although the Ontario profiles are in general noisier and shallower than those in ManitobaSaskatchewan, we do not believe that this explains the absence of the LIA. Regardless of the depth or noise level of the profiles, none of the individual inversions shows the LIA cooling. Two boreholes (logged by the Geological Survey of Canada in the early 1980s) located in northwestern Ontario but more than $500 \mathrm{~km}$ to the north of our study area do show a LIA signal. One possibility is that the LIA did not occur near Lake Superior because the local climate is affected by the lake.

- All regional GSTHs performed with selected temperature depth profiles show either a decrease or a stabilization of the warming rate in the recent past (20-40 years ago) before the most recent warming. This is in agreement with meteorological data from weather stations located in or near Central Canada, (as shown in Fig. 10 from Gosselin and Mareschal (2003)). These mean annual surface air temperature data, smoothed by averaging over an 11 year window, show a cooling trend from the 1940s to the 1970s. Despite the 20 year steps used in the regional GSTHs and the difference between surface air and ground surface temperatures, the GSTHs from all three regions appear well correlated with meteorological data.

Overall, the best method to obtain a valid GSTH using temperature depth profiles measured in boreholes seems to be to 1) Carefully select boreholes for which all external perturbations other than climate have been ruled out 2) perform a simultaneous inversion of the selected temperature depth profiles selecting a regularization parameter adjusted to the noise level and number of profiles used in the inversion and 3 ) in order to confirm the GSTH and remove any instability caused by the inversion, also perform an average of individual inversions done on selected profiles with the lowest possible regularization parameter.

\section{Conclusions}

In general, we find that selecting temperature depth profiles that are not affected by surface conditions yields a GSTH with the highest resolution. When profiles have been selected, simultaneous inversion of all the profiles and averaging of individual inversions yield almost identical results.

Simultaneous inversion of noisy temperature depth profiles usually fails to improve signal to noise ratio and turns out to be very unstable. When profiles that are affected by surface conditions can not be eliminated, it is preferable to average the GSTHs of individual inversions. The resolution is always poor but the average GSTH is stable.

All the temperature profiles and additional tables are available on the GEOTOP website at http://www.unites.uqam.ca/ geotop/geophysique/flux/index.htm.
Acknowledgements. The authors are grateful to two anonymous reviewers for their constructive comments. This work was supported by NSERC (Natural Science and Engineering Research Council of Canada) through a Discovery grant to JCM.

Edited by: V. Rath

\section{References}

Beltrami, H.: Surface heat flux histories from inversion of geothermal data: Energy balance at the Earth's surface, J. Geophys. Res., 106, 21 979-21 994, doi:10.1029/2000JB000065, 2001.

Beltrami, H. and Mareschal, J.-C.: Recent warming in eastern Canada inferred from geothermal measurements, Geophys. Res. Lett., 18, 605-608, 1991.

Beltrami, H. and Mareschal, J.-C.: Ground temperature histories for central and eastern Canada from geothermal measurements: Little ice age signature, Geophys. Res. Lett., 19, 689-692, 1992.

Beltrami, H. and Mareschal, J.-C.: Resolution of ground temperature histories inverted from borehole temperature data, Global Planet. Change, 11, 57-70, 1995.

Beltrami, H., Jessop, A. M., and Mareschal, J.-C.: Ground temperature histories in eastern and central Canada from geothermal measurements: evidence of climatic change, Global Planet. Change, 19, 167-184, 1992.

Beltrami, H., Cheng, L., and Mareschal, J.-C.: Simultaneous inversion of borehole temperature data for determination of ground surface temperature history, Geophys. J. Int., 129, 311-318, 1997.

Blackwell, D. D., Steele, J. L., and Brott, C. A.: The terrain effect on terrestrial heat flow, J. Geophys. Res., 85, 4757-4772, 1980.

Bodri, L. and Cermak, V.: Reconstruction of remote climate change from borehole temperatures, Global Planet. Change, 15, 47-57, 1997.

Carslaw, H. S. and Jaeger, J. C.: Conduction of Heat in Solids, Oxford University Press, New-York, second edn., 1959.

Cermak, V.: Underground temperature and inferred climatic temperature of the past millenium, Palaeogeogr. Palaeocl., 10, 1-9, 1971.

Clauser, C. and Mareschal, J.-C.: Ground temperature history in central Europe from borehole temperature data, Geophys. J. Int., 121, 805-817, 1995.

Gosselin, C. and Mareschal, J.-C.: Recent warming in northwestern Ontario inferred from borehole temperature profiles, J. Geophys. Res.-Solid Earth, 108, doi:10.1029/2003JB002447, 2003.

Guillou-Frottier, L., Mareschal, J.-C., and Musset, J.: Ground surface temperature history in central Canada inferred from 10 selected borehole temperature profiles, J. Geophys. Res., 103, 7385-7398, doi:10.1029/98JB00021, 1998.

Hansen, J. and Lebedeff, S.: Global trends of measured surface air temperature, J. Geophys. Res., 92, 13 345-13 372, 1987.

Harris, R. N. and Chapman, D. S.: Mid-Latitude $\left(30^{\circ}-60^{\circ} \mathrm{N}\right)$ climatic warming inferred by combining borehole temperatures with surface air temperatures, Geophys. Res. Lett., 28, 747-750, doi:10.1029/2000GL012348, 2001.

Hartman, A. and Rath, V.: Uncertainties and shortcomings of ground surface temperature histories derived from inversion of temperature logs, J. Geophys. Eng., 4, 299-311, doi:10.1088/ 1742-2132/2/4/S02, 2005. 
Huang, S., Pollack, H. N., and Shen, P. Y.: Temperature trends over the past five centuries reconstructed from borehole temperatures, Nature, 403, 756-758, 2000.

Jackson, D. D.: Interpretation of inaccurate, insufficient, and inconsistent data, Geophys. J. R. Astron. Soc., 28, 97-110, 1972.

Jessop, A. M.: The distribution of glacial perturbation of heat flow in Canada, Can. J. Earth Sci., 8, 162-166, 1971.

Jones, P. D., Wigley, T. M. L., and Wright, P. B.: Global variations between 1861 and 1984, Nature, 322, 430-434, 1986.

Jones, P. D., New, M., Parker, D. E., Martin, S., and Rigor, I. G.: Surface air temperature and its changes over the past 150 years, Rev. Geophys., 37, 173-200, doi:10.1029/ 1999RG900002, 1999.

Lachenbruch, A. H. and Marshall, B. V.: Changing climate: Geothermal evidence from permafrost in the Alaskan Arctic, Science, 234, 689-696, 1986.

Lanczos, C.: Linear Differential Operators, D. Van Nostrand, Princeton, N.J., 1961.

Lewis, T. J.: The effect of deforestation on ground surface temperatures, Global Planet. Change, 18, 535-538, 1998.

Majorowicz, J. A., Safanda, J., Harris, R. N., and Skinner, W. R.: Large ground surface temperature changes of the last three centuries inferred from borehole temperatures in the Southern Canadian Prairies, Saskatchewan, Global Planet. Change, 20, 227241, 1999.

Mareschal, J. C., Jaupart, C., Gariépy, C., Cheng, L. Z., GuillouFrottier, L., Bienfait, G., and Lapointe, R.: Heat flow and deep thermal structure near the southeastern edge of the Canadian Shield, Can. J. Earth Sci., 37, 399-414, 2000.

Mareschal, J. C., Jaupart, C., Rolandone, F., Gariépy, C., Fowler, C. M. R., Bienfait, G., and Carbonne, C.: Heat flow, thermal regime, and rheology of the lithosphere in the Trans-Hudson Orogen, Can. J. Earth Sci., 42, 517-532, 2005.

Menke, W.: Geophysical Data Analysis: Discrete Inverse Theory, no. 45 in International Geophysical Series, Academic Press, San Diego, 1989.

Misener, A. D. and Beck, A. E.: The measurement of heat flow over land, in: Methods and Techniques in Geophysics, edited by: Runcorn, S. K., Wiley-Interscience, New-York, pp. 11-61, 1960.
Nielsen, S. B. and Beck, A. E.: Heat flow density values and paleoclimate determined from stochastic inversion of four temperature-depth profiles from the Superior Province of the Canadian Shield, Tectonophysics, 164, 345-359, 1989.

Parker, R. L.: Geophysical Inverse Theory, Princeton University Press, Princeton, New Jersey, 1994.

Perry, H. K. C., Jaupart, C., Mareschal, J. C., and Bienfait, G.: Crustal heat production in the Superior province of the Canadian Shield and in North America, inferred from heat flow data, J. Geophys. Res., 111, B04 401, doi:10.1029/2005JB003893, 2006.

Pinet, C., Jaupart, C., Mareschal, J.-C., Gariepy, C., Bienfait, G., and Lapointe, R.: Heat flow and structure of the lithosphere in the eastern Canadian shield, J. Geophys. Res., 96, 19941-19963, 1991.

Pollack, H. N., Shen, P. Y., and Huang, S.: Inference of ground surface temperature history from subsurface temperature data: Interpreting ensembles of temperature logs, Pure Appl. Geophys., 147, 537-550, 1996.

Pollack, H. N., Huang, S., and Shen, P. Y.: Climate change records in subsurface temperatures: A global perspective, Science, 282, 279-281, 1998.

Press, W. H., Teukolsky, W. T., Vetterling, W. T., and Flannery, B. P.: Numerical Recipes in Fortran. The Art of Scientific Computing, Cambridge University Press, Cambridge, UK, 1992.

Shen, P. Y. and Beck, A. E.: Least squares inversion of borehole temperature measurements in functional space, J. Geophys. Res., 96, 19965-19979, 1991.

Tikhonov, A. N. and Arsenin, V. Y.: Solution of ill posed problems, Wiley, New-York, 1977.

Vasseur, G., Bernard, P., Van de Meulebrouck, J., Kast, Y., and Jolivet, J.: Holocene paleotemperatures deduced from geothermal measurements, Palaeogeogr. Palaeocl., 43, 237-259, 1983.

Wang, K.: Estimation of ground surface temperatures from borehole temperature data, J. Geophys. Res., 97, 2095-2106, 1992.

Wang, K., Lewis, T. J., Belton, D. S., and Shen, P. Y.: Differences in recent ground surface warming in eastern and western Canada: Evidence from borehole temperatures, Geophys. Res. Lett., 21, 2689-2692, 1994. 